\title{
Real Fábrica de Paños Superfinos de la Compañía y Fábrica Real de Paños de Ortiz de Paz
}

\author{
Francisco javier Mosácula María *
}

\section{RESUMEN}

La industria textil lanera segoviana, cuya época de mayor esplendor se desarrolla a finales del siglo xvi, cayó lenta, pero paulatinamente, hasta la segunda mitad del siglo xvII en que presenta sintomas de franca recuperación, para precipitarse hasta su desaparición en el siglo xix. Primeramente, se analiza la política industrial llevada a cabo por el Estado y su incidencia en Segovia, con el fin de comprender mejor las causas que llevaron a la Corona y a la iniciativa privada a fundar la primera realización

fabril de la historia de la pañeria segoviana. Las manufacturas reales habian comenzado a funcionar desde primeros de siglo. Aunque la concesión de privilegios y la entrega de caudales por parte de la Hacienda

supusieron una verdadera sangría para el Estado, la experiencia no fue del todo negativa, pues facilitaron la

\section{ABSTRACT}

The wool textile Segovian industry, whose most magnificent period takes place during the last years of the $16^{\text {th }}$ century, fell down, slowly but gradually, till the second half of the $18^{\text {th }}$ century, when it presents symptoms of full recovering, to rush towards its extinction in the $19^{\text {th }}$ century. First, the industrial politics carried out by the Government and its influence in Segovia are analized, in order to understand the reasons which made the Crown and the private enterprise found the first manufacturing achievement in the history of the Segovian drapery. The Royal manufacturing had started to work from the beginning of the century. Despite the granting of privileges and the delivery of properties carried out by the Treasury were a continuous loss for the State, the experience was not

* UNED. 
entrada de técnicas y maquinarias extranjeras y significaron una renovación en el campo de las ideas productivas. La efímera vida de la Real

Fábrica de paños superfinos de la Compañía, cuya estructura técnica y sus relaciones sociales de producción se ajustaban a la típica «manufactura

capitalista", significó el primer paso para que la iniciativa privada iniciara la aventura de sacar a Segovia del estado de postración en que se encontraba. La Real Fábrica de paños de Ortiz de Paz, fue la culminación de este proceso. only negative, since they provided the entry of foreign techniques and machinery and signified a renewal in the field of profitable ideas. The ephemeral life of the Company Royal extra-fine cloths factory, whose technical structure and social relationships of production fit the typical "capitalistic manufacture", signified the first step for the private enterprise to begin the adventure of taking Segovia out of the prostration condition in which it stood. The royal clothing factory Ortiz de Paz was the culmination of this process.

\section{INTRODUCCIÓN}

El ansia de conquistar nuevos mercados y el de conservar los existentes por parte de las potencias en el siglo XVIII europeo, dio lugar a un proceso constante de innovación tecnológica que conocemos con el nombre de Revolución Industrial. Este proceso se inició en Inglaterra, pero, paulatinamente, se fue extendiendo al resto de las naciones europeas, en mayor o menor grado.

En España, bajo el timón estatal, cristalizaron importantes reformas políticas, administrativas y culturales. Fue al Estado a quien le correspondió un papel nada desdeñable en la «reforma económica». En líneas generales, la política industrial fue variando a lo largo del siglo, a impulsos de los criterios de los hombres de gobierno, funcionarios, economistas y empresarios, y se pasó de un sistema mercantilista a otro marcado por un liberalismo incipiente.

En la primera mitad se consolidó el ordenamiento mercantilista. Sus propósitos no eran otros que formar una nación comerciante y aglutinar una nación industriosa. Felipe $V$, eliminó las barreras internas, y procedió a llevar a cabo una reforma tributaria y de la moneda, en vistas a mejorar las relaciones comerciales. En cuanto a la industria, las metas se centraron en lograr el control estatal de las fábricas y en llegar a una autosuficiencia. Su política se caracterizó por la legislación favorable a los gre- 
mios, el fomento de la industria - a base de franquicias y privilegios monopolísticos--, la creación de manufacturas estatales y el proteccionismo en el comercio exterior.

Los años que dan comienzo a la segunda mitad de siglo, desde 1750 a 1770 , significaron una etapa de transición hacia un tímido liberalismo. Se empezó a atacar a los gremios y se extendieron a todas las fábricas en general, los privilegios y exenciones que antes se gozaban de un modo particular.

El afán de reformas fue la nota típica de este periodo. Por una parte, en el último tercio de siglo, la fisiocracia revalorizará el «orden natural», y por otra, confluirá con el individualismo y el liberalismo económico. Además de proceder a la reforma agraria del país, una serie de criterios liberal-económicos elevaron el estímulo y la iniciativa, y suscitaron un replanteamiento de los criterios teóricos del comercio y de la industria. Se entabló una lucha abierta contra la ordenación gremial - que coartaba la iniciativa de los artesanos-, y, en la década de los noventa, prácticamente podríamos decir que se había consagrado la libertad del trabajo y la innovación tecnológica.

España no fue ajena al proceso de transformación industrial que se operaba en Europa, aunque éste se produjo de forma tibia y, a veces, marginal. De todos los modos, a finales del siglo XVIII, la industria española se acercaba a la francesa, y, a principios del siglo xIX, casi llegaba a la altura de la inglesa.

Pero todo este proceso no se había iniciado con el siglo, sino que hundía sus raíces en el siglo anterior. A partir de 1680, se produjeron algunas reformas, como la creación de la Junta de Comercio, la preocupación de traer técnicos extranjeros, o la de eliminar las normas que afectaban a la deshonra legal del trabajo, que significaron el umbral del reformismo del siglo XVIII.

A principios del XVIII, España estaba a falta de moderna tecnología, de trabajadores especializados, de capital, de organización mercantil y de comunicaciones. Salvado el bache de la Guerra de Sucesión, el siglo XVIII será un periodo continuado de crecimiento industrial, empujado por la política económica del Estado, que significará un desarrollo del país en todos los aspectos.

Países como Inglaterra, Holanda y Francia, tenían una larga tradición manufacturera y más avanzada que la de España. Además, se habian ganado sus mercados desde tiempo atrás, debido a sus precios más bajos y a la influencia de las modas; pues su calidad, a veces, quedaba por debajo de la de los productos nacionales. 


\section{ESTADO Y EVOLUCIÓN DE LA INDUSTRIA TEXTIL LANERA EN SEGOVIA (SIGLOS XVIAL XIX)}

Al filo de 1500, los caracteres fundamentales de la producción textil en la submeseta norte, eran los siguientes: el proceso productivo se realizaba en el marco de la pequeña empresa familiar domestic system, diseminadas por el ámbito rural y por la ciudad; la calidad de los paños era baja - dieciochenos e inferiores-y hechos con lana basta; se pretendía satisfacer una demanda poco exigente; y no existía ordenación gremial de la producción. En cambio se hallaba muy difundido el sistema de trabajo a domicilio, denominado putting-out system o verlag system '.

La formación de las Ordenanzas Generales para todo el reino, cuyo primer proyecto se realizó en 1495 , exigió la adaptación de la pañeria rural a la pañería urbana, con las consiguientes transformaciones técnicas. Hasta entonces todo el proceso productivo se desarrolló en las empresas familiares. Como las Ordenanzas Generales definitivas no fueron publicadas hasta 1511, Segovia, entre tanto, fue adaptando su producción al sistema gremial, mediante la implantación, con carácter transitorio, de las ordenanzas de Cuenca ${ }^{2}$.

El proceso de transformación de la industria textil, que se inició con las Ordenanzas Generales a principios de siglo, no concluyó hasta 1560-90. Durante este largo periodo de tiempo, se fueron concentrando las labores de fabricación del paño en el núcleo urbano. Así el verlagssystem vio limitada su difusión en el ámbito rural a la hilatura, sobre todo, en los pequeños núcleos de población cercanos a la ciudad, que hilaban lanas finas a las órdenes de los mercaderes de Segovia. Y, además, el proceso de fabricación quedó enmarcado dentro del ordenamiento gremial. Pero la continua evolución en este aspecto y la concentración técnica de las labores y de la propiedad de los medios de producción, llegó a rebasar el ordenamiento gremial, dando origen a algunas manifestaciones de factory system o sistema de manufactura ${ }^{3}$.

Durante el reinado de Felipe II se pidió que se dejaran de hacer los paños $36^{\text {enos }}, 38^{\text {enos }}, 14^{\text {enos }}, 18^{\text {enos }}$ y se centrara la producción en los $20^{\text {enos }}$ y $24^{\text {enos }}$, es decir, los famosos paños finos de Segovia.

\footnotetext{
IRadiel Murugarren, P., Evolución de la industria textil castellana en los siglos XIII-XVI. Salamanca, 1974 , pp. 380 y ss.

ibidem, p. 389.

3 Garcia Sanz, Ángel, Desarrollo y Crisis del Antiguo Régimen en Castilla la Vieja. AKAL S. A. 1986, p. 213.
} 
«Por la ley 25 de las Ordenanzas de 1511 se señalaban los hilos y marco de peyne para treintenos; pero de resulta de quexa dada por los Procuradores de Cortes que hicieron presente la careza de los paños, y que por ser tan finos, los ciudadanos y gente llana no se podía vestir: se prohibió en la ley $1 .^{a}$ de la Pragmática de 1549 hacer paños de mayor ley y suerte de veintiquatrenos; esta prohibición parece que duró en Segovia hasta el año 1733, que en el artículo 30 de la Ordenanza para esta fábrica se dieron reglas para paños de suertes superiores, que dice ser nuevo establecimiento" ${ }^{4}$.

Quizá en aquel tiempo pareció conveniente para la "fábrica común» de Segovia, dejar de producir estos paños de calidad superior (superfinos) y conformarse con la elaboración de paños finos, pues el prestigio del paño segoviano, era superior al que provenía del extranjero, y, precisamente, los paños que daban fama a Segovia, eran los que se conocían con el nombre de "paños finos de Segovia». Pero lo que sí resultó evidente con el paso del tiempo, fue que, aprovechándose de esta prohibición, las fábricas extrajeras hicieron privativo suyo este comercio de paños superfinos y aunque desde el reinado de Felipe $V$ se procuró su fabricación, las dificultades y gasto de su establecimiento, y las ventajas que en los tintes, máquinas y otros aspectos organizativos lograron los extranjeros, dificultaron sobremanera la vuelta a esta producción de superior calidad.

Así que, Segovia, en su momento de mayor esplendor (el periodo comprendido entre 1579 y 1585), y fabricando paños finos, produjo 16197 piezas de paño de 40 varas $(33,4$ metros) y tuvo en funcionamiento unos 600 telares y 15 batanes. La ocupación en el sector textil en estas fechas fue del $60 \%$ de la población activa ${ }^{5}$.

El siglo xVII en Segovia, y en lo que respecta a la producción industrial, fue de franca decadencia. Aunque la mortandad producida como consecuencia de la peste de 1599 fue muy numerosa, parece ser que la ciudad tardó poco tiempo en recuperarse. Peor debió de ser el periodo comprendido entre 1625 y 1635. Observando la evolución del número de bautizados en las parroquias de los "arrabales» de Segovia - donde estaban avecindados la mayoría de los trabajadores del paño-, estos datos sugieren que la producción se estancó hasta alrededor de 1610, comenzando un suave declive hasta el año 1627, para a continuación precipitarse en la caída hasta 1634 .

4 Archivo Municipal de Segovia. Memorias de la Sociedad Económica de Amigos del País de Segovia. pp. 308 y 309.

5 García Sanz, Ángel, op. cit., p. 215. 
El declive en el número de bautizados, es el indicador indirecto que nos informa, sobre todo, que, bien fuera por la emigración o bien fuera por la mortandad catastrófica, la realidad es que la pérdida de la población adulta, por fuerza tenía que disminuir el número de nacimientos. $Y$ en este caso concreto, la pérdida de población significaba la caída en la producción, al tratarse de población empleada en las manufacturas del paño. Estos ocho años son los más dramáticos de la historia de la pañería segoviana, por cuanto marcan la ruptura entre la época más brillante de esta actividad y el inicio de una larga fase de más de doscientos años de lenta decadencia, hasta su completa desaparición ya en el siglo XIX. Las alteraciones del valor de la moneda y las malas cosechas durante estos ocho años dramáticos, tuvieron como consecuencia una serie de males irreversibles. Una fortísima emigración, provocó una pérdida demográfica estimable en, al menos, la tercera parte de la población de la ciudad. Así lo muestran los registros parroquiales de bautismo de las parroquias arrabaleras. Si en otras ocasiones la población de había recuperado gracias a la emigración, en este caso no ocurrió así.

En el reinado de Felipe IV había en Segovia 300 telares y 7 batanes, pero la decadencia continuó y en 1692 solamente estaban en activo en la ciudad 159 telares $^{6}$.

En la interpretación de los datos de producción de este siglo, Larruga sufre un grave error. Como no cuenta con noticias precisas para el siglo XVI y sí conoce que en los reinados de Felipe III y Felipe IV se favoreció extraordinariamente desde la administración a la fábrica de Segovia, deduce que debió de ser durante estos reinados cuando la industria segoviana alcanzó el mayor grado de crecimiento; de ahí, concluye, que las cotas de producción de finales del siglo XVIII, fueron similares a las de máxima producción. La verdad es que hacia la mitad del siglo XVII, se producía la mitad que en 1580 y a finales del mismo siglo la cuarta parte. Por tanto, en el periodo de máxima producción del siglo XVIII, se produjeron la mitad que en el año 1580, es decir, lo mismo que a mediados del siglo XVII.

Causas de esta decadencia son el atraso técnico debido a la reglamentación gremial, a la inflación de la plata y el cobre, y al aumento del crédito; lo que determinó un aumento de los costes de producción y supuso la eliminación de los mercados a los paños segovianos, dando paso a los paños extranjeros.

Otra causa de la decadencia, fue el desvío de la inversión del capital, hacia otros negocios que no requerían capital fijo. Es decir, la venta de lana.

- Larruga, Eugenio. Memorias Políticas y Económicas... Tomo XII. Madrid 1791, p. 332. 
Esta crisis no sólo fue cuantitativa sino también cualitativa. Los productos perdieron calidad con respecto al siglo xvI. A los fabricantes en 1625 se les concedió por Cédula, el tanteo de la mitad de las lanas finas que los comerciantes adquirían para revender. Los ganaderos protestaron diciendo que el tanteo entorpecía la exportación. En estas circunstancias, los fabricantes de tejidos de mediana y baja calidad, se consolidaron en la industria segoviana y en 1635 se constituyeron en gremio independiente. Además, otro cambio cualitativo fue la dispersión de la producción, quedando del factory system solamente el recuerdo.

Sincronizados con los cambios de base material, se produjeron transformaciones en la valoración social del fabricante. El ideal industrial de $X V I$ se vio sustituido por el ideal ganadero de XVII .

En el siglo XVill, el objetivo primordial con el que nació la Sociedad Económica Segoviana de Amigos del País, fue el de descubrir las causas de la decadencia de la "antigua fábrica" de paños ${ }^{8} y$, a continuación, proponer medidas oportunas para restaurar la producción. En este siglo, se volverá a producir una concentración en el proceso de producción -como en el siglo XVI-, que culminará a finales de siglo con la aparición de las «manufacturas de paños».

En 1691 el $98,9 \%$ de los propietarios tenían menos de 4 telares y reunían el $96,5 \%$ de ellos. En 1778 los que tenían menos de 4 telares eran el $50 \%$ y reunían el $21 \%$ del total de telares ${ }^{9}$. Hacia 1751 , según el Catastro del Marqués de la Ensenada, los fabricantes eran 89 y tejían 5223 paños ${ }^{10}$. En 1801 los fabricantes eran 75 y confeccionaban 4525 paños, sin contar el establecimiento de Ortiz de Paz, que de 1784 a 1800 había producido 900 piezas anuales aproximadamente ${ }^{11}$. Lo que significa una acentuación de la concentración de la producción. Esto implica la pérdida de la propiedad de los medios de producción por parte de los humildes, comenzando un proceso de proletarización en beneficio de los poderosos. El número de propietarios de telares se redujo entre 1691 y 1778 en un $66,5 \%$.

\footnotetext{
LE FLEM, Jean Paul, Vraies et fausses splendeurs de l'industrie textile ségovienne (vers 1460 - vers 1650). Firenze, Leo S. Editore, 1976.

\& Cuando hablamos de la Antigua Fábrica de paños de Segovia no hay que entenderla como una instalación fabril, sino como el conjunto de los fabricantes - cada uno con su propio taller y sus propias instalaciones - que se regian por las mismas ordenanzas gremiales.

Larruga, Eugenio, op. cit., Tomo XI, pp. 325-331.

10 Archivo Provincial de Segovia, Sección de Hacienda. Catastro del Marqués de la Ensenada, leg. 265 (Segovia), libro de Respuestas Generales, pregunta 32.

11 QuINTANILLA, Mariano, La fabricación de paños a comienzos del siglo XIX. Estudios Segovianos, $\mathrm{n} . \stackrel{0}{30}$, tomo $\times(1958)$, pp. 534-536.
} 
Dos ejemplos de altos niveles de concentración lo constituyeron la Real Fábrica de paños superfinos de la Compañía y la Fábrica Real de paños de Ortiz de Paz. La instalación 1763 de la Compañía, supuso la primera realización verdaderamente fabril en la historia de la pañería segoviana. Este establecimiento que se privatizó en 1779 a favor de Laureano Ortiz de Paz, fue imitado - ya en el siglo xIx-, por algunos empresarios, que pretendieron así superar el tradicional marco organizativo del verlagssystem, a fin de modernizar la producción industrial segoviana. Lamentablemente fueron pocos, y si en 1800 la producción rebasaba los 5000 paños, en 1818 bajó a 3500 y en 1848 a 60 paños. El descenso brusco de produjo en 1825-40, después de algunos episodios "luditas" que ocasionaron incendios y la pérdida de los emplazamientos industriales.

\section{POLÍTICA INDUSTRIAL LLEVADA A CABO POR EL ESTADO EN SEGOVIA EN EL SIGLO XVIII}

La decisión de crear la Diputación vitalicia en 1708, grupo formado por 12 fabricantes encargados de controlar la producción, es una prueba más de la legislación favorable a los gremios llevada a cabo por la Corona, en la primera mitad del siglo XVIII ${ }^{12}$.

Se tomó la medida para tratar de evitar la decadencia de la antigua fábrica, y en base a que no había personal con la suficiente capacidad y experiencia, como para ejercer la veeduría que garantizase la calidad de los paños. La medida fue contraproducente, pues si de lo que se trataba era de mejorar la calidad de los paños, lo único que se consiguió fue facilitar los medios de corrupción a este grupo de privilegiados, y crear un mal ambiente entre el resto de los fabricantes, que vieron así perjudicados sus intereses por la actuación arbitraria de los diputados.

El 14 de abril de 1714, D. José de Grimaldo, secretario de Estado de S. M. y del Despacho de Guerra y Hacienda, remitió al Superintendente de la fábrica de Segovia una carta, en la que el rey deseaba por todos los medios que fuesen practicables, se apoyasen, fomentasen y aumentasen las fábricas de paños de Segovia. Este señor encontró que las cuatro especies de carnes, vino, aceite y pescado, estaban muy cargadas de impuestos. El que más el vino, que además de millones y derechos de Hacienda, se le cargaba con 64 maravedís cada arroba y otros 64 más, que se ha-

12 Larruga, Eugenio, op, cit., tomo XII, p. 5 
bían subido a partir de 1712 por nuevas disposiciones ${ }^{13}$. Se trataba de bajar los precios de los artículos de primera necesidad, para que así, los trabajadores del paño, no se vieran obligados a trabajar de forma rápida y precipitada, con el objeto de alcanzar una mayor producción que les permitiera alimentar a sus familias. El trabajo desarrollado de forma más o menos sosegada subiría la calidad del producto. Pero para ello era necesario subir el salario del trabajador o bajar los precios de los artículos de consumo.

Todas las medidas tomadas por la Corona, se encaminaron a intentar cubrir los mismos objetivos: aligerar la carga impositiva de los fabricantes de paños, e intentar que la calidad de los paños nacionales se pusieran a la altura de la de los extranjeros. El 12 de octubre de 1718, se les concedió la exención de alojamientos de tropas. Pero el problema de la mala calidad de los productos era endémico. Por la carestía de la vida y la escasez de dinero, se prefería pagar a los oficiales y aprendices en género. Estos veían de esta manera reducida aún más su capacidad adquisitiva, lo que repercutía en la calidad de todo el proceso productivo. A un cardado de la lana de forma precipitada, le sucedía un hilado de mala calidad. Con malos hilos, los tejedores malamente podian tejer en condiciones sus paños. Y lo mismo podemos decir de los empleados de los batanes. El resultado era siempre el mismo. Los paños segovianos no podían competir con los extranjeros en ninguno de los mercados.

Si a principios del reinado de Felipe $V$, había 300 telares, 40 tintes y 7 batanes; en 1724 eran 120 telares, 20 tintes y 4 batanes los que habia; continuaba la decadencia de la "fábrica" de Segovia y se achacaba a que no tenían franquicia alguna. Los administradores de rentas reales recargaban a los fabricantes en exceso - 34000 reales de encabezamiento al año-, por los materiales necesarios para la manufactura de los paños, aceite, jabón, etc. ${ }^{14}$.

La iniciativa privada también trató de mejorar la calidad de los productos y no sólo fue la administración la que tuvo este empeño. En 1723, Juan de Buenlabrar, fabricante de paños y uno de los diputados de la fábrica, puso dos telares de superfinos con maestros y oficiales traídos de Guadalajara. Después de la oposición por parte de los veedores de la fábrica, a que trabajasen operarios no examinados en Segovia, la Junta de Comercio dio facultad a Buenlabrar para que continuara con su empresa ${ }^{15}$.

\footnotetext{
lbidem, p. 11

lbidem, o. 25.

lbidem, p. 39
} 
Otro caso de empresario emprendedor fue el de D. José Ramiro. En 1734 fabricó un tipo de paño que no estaba recogido en las ordenanzas recientemente aprobadas del año 1733. Se trataba de una telilla mezcla de seda y lana muy duradera, a imitación de los paños extranjeros, pero que no triunfó por la envidia del resto de los fabricantes, y porque no le fue concedido el monopolio de fabricar en exclusiva esta clase de tela, además de no concederle la exención de tributos que pedía para los diez años siguientes ${ }^{16}$.

En la década de los treinta siguieron las peticiones relativas a la exención de impuestos. Se solicitaron la libertad de alcabalas y cientos para la primera venta del paño en cualquier ciudad, villa o feria en que se ejecutase. También pidieron franquicias para su exportación a las Indias. La voluntad por mejorar la calidad e incentivar la producción era evidente por parte de todos. Con este fin se redactaron y aprobaron unas nuevas ordenanzas en el año 1733. Una de las novedades fue la introducción de la figura del superintendente de fábrica. Enseguida se empezó a notar su presencia. Insistió en la obligación de cardar al potro, la introducción de nuevas mezclas de colores para imitar a los paños extranjeros y, en definitiva, toda una serie de mejoras técnicas encaminadas a conseguir una producción competitiva. Pensó en la necesidad de una prensa para dar mayor perfección al acabado de los paños, pero la oposición por parte de los diputados a acatar su autoridad, acabó por mandar al traste todos los intentos. La corrupción existente y la elaboración fraudulenta introducida en todo el proceso de fabricación, fue un mal endémico muy difícil de superar; aunque en honor a la verdad, hay que decir que, en los años centrales del siglo XVIII, las soluciones que se pusieron en práctica para tratar de superar los fraudes, fueron muchas y muy variadas.

Si la primera mitad de siglo fue la de las peticiones por parte de los fabricantes, la segunda fue la de las concesiones por parte del Estado.

La limitación de gracias y exenciones solamente a determinadas fábricas, había resultado perjudicial para las otras. Su Majestad, por Real Cédula de 18 de noviembre de 1779 , y para animar el fomento de los tejidos y manufacturas de lana, cuyo vasto consumo podía proporcionar honesta y útil ocupación a una gran parte de sus vasallo, se decidió por unificar la reglamentación de todas las fábricas de lana, sin excepción de ninguna clase y calidad ${ }^{17}$. Se concedió a las fábricas de Castilla libertad de alca-

16. Ibidem, p. 85.

17 AMIS, Real Cédula, sig. XXV1-764-21 
balas y cientos, en las ventas al por mayor y por menor que se hiciesen a pie de fábrica y en las tiendas de los mercaderes, y sólo se exigiría un $2 \%$ sobre el precio de la fábrica. A su vez se subió un $10 \%$ la venta de los paños extranjeros. Igualmente, se liberó de pagar alcabalas y cientos, a los paños que se llevaran a los puertos habilitados para el comercio libre con América. Con el fin de rebajar los precios de los productos necesarios en el proceso de fabricación, todos los fabricantes gozarían de libertad de los derechos de millones del aceite y el jabón que se consumiera en dichas maniobras. Además, se facilitaría la entrada de los paños de Castilla en los otros reinos pertenecientes a la Corona, con otra serie de privilegios. También se concedió a todos los fabricantes, la libertad de derechos reales y municipales de aduanas, para todos los simples e ingredientes procedentes del extranjero; como también, el de las máquinas e instrumentos que modernizaran las instalaciones españolas. Igualmente gozarían de libertad de los mismos derechos, todos los tejidos que fueran exportados al extranjero. Por último, se concedió a los fabricantes de paños, el privilegio del tanteo de las lanas sobre cualquier comprador natural o extranjero.

El día 8 de mayo de 1781 se ampliaron estos privilegios, al dar facilidades a los fabricantes para que construyeran tintes y batanes, en los lugares que creyesen más convenientes; la facultad de denunciar los paños cuyas marcas hubiesen sido falsificadas; el derecho a portar armas defensivas, etc.

Si hasta ahora los privilegios habían consistido en franquicias y exenciones, en el último cuarto de siglo las concesiones serian de carácter técnico. El 22 de junio de 1787 se concedió a todos los fabricantes de cualquier especie o calidad que fueren, libertad para tener el número de telares que creyeren convenientes sin limitar su número ${ }^{18} . \mathrm{Y}$, por último, dentro de estas normas encaminadas a conseguir una mayor libertad en el proceso de fabricación, se autorizó por Real Cédula a todos los fabricantes de tejidos, a tener la facultad de poder inventarlos, imitarlos y variar libremente sus características técnicas, con el fin de conseguir cada vez más productos capaces de competir con los fabricados en el extranjero ${ }^{19}$.

Para terminar de completar todas estas libertades, en 1789 aprobó por orden de S. M. la Real Junta de Comercio Moneda y Minas, el Reglamento Interino para el régimen y gobierno de la antigua fábrica de paños de la ciudad de Segovia.

\footnotetext{
18 AMS, Real Cédula, sig. XXV1-765-1.

19 AMS, Real Cédula, sig. XXVIII-817-21.
} 


\section{LA REAL FÁBRICA DE PAÑOS SUPERFINOS DE LA COMPAÑÍA}

Una de las causas que más contribuyó a que la antigua fábrica de paños de Segovia no pudiera perfeccionarse, fue el gran número de fabricantes existentes en la ciudad. Además de no reunir, ni ellos ni sus operarios, los conocimientos necesarios para elevar esta industria al grado de perfección que iba adquiriendo en el extranjero, ejecutaban sus maniobras en locales reducidos, donde no era posible el establecimiento de la nueva maquinaria que demandaba esta industria; careciendo, además, del capital necesario para desarrollar sus actividades a una escala conveniente.

Como hemos visto más atrás, la inquietud de los fabricantes por mejorar la calidad de la producción y con ella la competitividad, era evidente. Por esta razón, en el año 1761, el Marqués de Esquilache propuso al Intendente de Segovia, don Pedro Girón, que con acuerdo de los diputados de la fábrica, estudiasen los medios para el establecimiento de una nueva manufactura, en la que se hubieran de construir paños de superior calidad y susceptibles de hacer competencia a los mejores que viniesen del extranjero.

Se convocó una junta general, no sólo de los diputados de la fábrica sino de todos los fabricantes, con el fin de demostrar la utilidad del proyecto y la necesidad de reunir para ello un fondo suficiente, para montar en debida forma un establecimiento de esta naturaleza. Con objeto de ir avanzando, el 17 de septiembre de 1761, se presentó en junta general un proyecto de bases para constituir dicha Compañía. Este proyecto se remitió al Marqués de Esquilache, quien, con fecha 11 de mayo siguiente, contestó manifestando:

«... que S. M., se había servido interesarse en esta Compañía por cantidad de 400000 reales, que se convocasen nuevamente a los diputados y maestros de la fábrica, y que de común acuerdo, se formasen las reglas e instrucciones con que debería establecerse la nueva fábrica...» ${ }^{20}$.

Se consiguió el acuerdo de todos para elaborar granas y paños superfinos de las clases $30^{\text {enos }} 34^{\text {enos }}$ y $40^{\text {enos }}$, sempiternas, sargas, bayetas, mantas finas y cualquier otro tejido o labores de lana.

En junta general de 25 de noviembre de 1762, se acordó hacer a S. M. la propuesta para el cargo de directores a D. José Entero Hergea y D. Fe-

20 A. M. S. LAINEZ, Marcelo, Revista de la Sociedad Económica Segoviana de Amigos del País, III, núm. 7, 18 de mayo de 1878. 
lipe Herranz - diputados vitalicios de la fábrica antigua- y a D. Diego Antonio Robledo, que lo era anual. Para contador fue elegido D. Bernardo Pérez y para tesorero fue propuesto D. José García Carril. Esta propuesta fue aprobada por S. M. en el Buen Retiro, el 6 de enero de 1763, y se fijaron los sueldos de los directores en 150 ducados; el del contador, en 200 ducados y 400 cuando estuviese la fábrica en funcionamiento con 20 ó 25 telares; y para el tesorero, la cantidad de 100 ducados, todos ellos anuales.

Se acordó también que cuando viniesen aprobadas las ordenanzas, se habia de entregar al tesorero de la Real Compañía la mitad de lo que cada uno de sus accionistas tenía ofrecido, por considerarse suficiente para la compra de la casa, obra que hubiese que hacer en ella y adquisición de utensilios y materiales para el inicio de la fabricación. Las ordenanzas fueron aprobadas por S. M., en virtud de Real Cédula el 12 de enero de 1763.

En dichas ordenanzas, en su artículo primero, se disponía que la Compañía se instalase bajo el patrocinio de la Virgen de la Fuencisla, la protección de S. M., la del presidente de la Junta de Comercio y de la del Intendente de la ciudad de Segovia.

El capital previsto que se debía de invertir era de 999.000 reales repartidos en 333 acciones de 3000 rs. cada una. El erario real se comprometía a aportar 400.000 rs. Debían de ponerse en funcionamiento entre 20 y 25 telares. En los 66 artículos de las ordenanzas se concedían a la entidad los privilegios y exenciones usuales en este tipo de establecimientos, y se regulaba con meticulosidad todo el proceso productivo, muy en línea con la ordenación gremial.

Los primeros artículos se centran en el precio de las acciones y en los derechos y deberes de los accionistas, para dar paso después a las obligaciones de los cargos directivos: directores, contador y tesorero. Acto seguido, se ocupan del cargo de almacenista y director de maniobras, para pasar a continuación al articulado relativo a los aspectos organizativos y técnicos propiamente dichos. Lo característico de estos artículos es que las normas que se relacionan, son del más puro estilo gremial. En ellos se especifica que se pondrían en funcionamiento de 20 a 25 telares; la calidad de los paños a fabricar, que tendrían que ser los llamados superfinos; los operarios que debían trabajar en la fábrica, puntualizando que se podrían emplear en ella aquellos operarios de la fábrica común que lo desearan y, sin embargo, dicha fábrica no podría tomar ningún obrero de la Compañía; los veedores de la fábrica común no tendrían jurisdicción en la de la Compañía, etc. 
Continúa el articulado de las ordenanzas con las reglas que se han de observar en la fabricación de los paños y con las gracias y franquicias que S. M. había concedido a la compañía ${ }^{21}$.

La estructura técnica del establecimiento y las relaciones sociales y técnicas de producción, se ajustaban a una típica «manufactura capitalista»: propiedad de los medios de producción por parte del capitalista; concentración de un número considerable de obreros asalariados que trabajaban al mismo tiempo, en el mismo lugar y bajo el mando de los dueños del capital o sus delegados; integración de maniobras y unidad del trabajador con el instrumento que manejaba.

De las cuentas de esta Compañía resulta que costó entonces la casa donde se instaló la cantidad de 40.887 rs. y 6 mrs., y se gastaron en las obras que se ejecutaron 100.919 rs. Importaron la adquisición de pertrechos de oficinas por importe de 21.681 rs. y 4 mrs., y de materiales, utensilios y manufacturas, la cantidad de 272.002 rs. y $22 \mathrm{mrs}$.

El dinero que habian adelantado los accionistas ascendía a 431.400 rs., de los que 200000 procedían del erario real; y los gastos que había tenido para ponerla en funcionamiento, ascendían a 435.489 rs. y $32 \mathrm{mrs}$. Con lo que el alcance a favor de la Compañia era de 4.089 rs. y $32 \mathrm{mrs} .{ }^{22}$.

La dirección consideró conveniente no pedir a los interesados más que la mitad del valor de sus acciones, mientras no se hallase la fábrica trabajando a pleno rendimiento. Sin embargo, ya se dieron cuenta de que la poca salida de los paños, y los elevados precios de la lana, aceite, jabón y demás ingredientes para tintes, ponían en peligro la estabilidad de la empresa. Empezaron a funcionar solamente 8 telares y se crearon cuatro escuelas de hilazas para surtir al establecimiento.

En junta de accionistas, celebrada el 22 de enero de 1763, se acordó hacer venir de la Real Fábrica de Paños de Guadalajara a Baltasar Pérez para que desempeñase los cargos de almacenista y director de maniobras, con un sueldo de 350 ducados anuales, quien trajo consigo varios operarios instruidos en las maniobras necesarias para hacer paños superfinos, ya que en Segovia no los había suficientemente preparados. Vinieron acompañados de sus esposas, que eran entendidas en estas maniobras, sirviendo de maestras de hilado unas, de espinzado otras, de picados de los paños y mezclas otras tantas, etc. ${ }^{23}$

21 Larruga, Eugenio, op. cit. , pp. 228-246.

22 Ibidern, pp. 247-248.

23 LAINEZ, Marcelo. Apuntes Históricos de Segovia. Estudios Segovianos. Tomo XVI, p. 403 
En el año 1766 falleció Baltasar Pérez y vino en su lugar, también de Guadalajara, Juan Pedro Fay, que primero cobró 10 reales y después hasta 15 reales diarios.

A partir del año 1766, se solicitaron más franquicias para poder vender los paños en todo el reino y, sobre todo, en Madrid, donde era más regular el consumo de la ropa superfina. Se alegaba que las fábricas de Guadalajara y San Fernando sí disfrutaban de tales franquicias. Por Cédula de 30 de julio de 1767 se concedía, además de la libertad de alcabalas y cientos a los géneros vendidos a pie de fábrica, ampliar por un periodo de cinco años a los que se vendiesen en los puertos que mantenían comercio libre con América. Pero con esta medida se arreglaba poca cosa, pues en el mercado de Madrid, que era el más importante para los paños segovianos, seguian siendo beneficiados los paños de San Fernando y Guadalajara, con mejores ventajas fiscales que los segovianos.

La situación financiera de la fábrica se fue deteriorando a pesar de que el capital inicial se vio incrementado en 122.600 rs., procedentes de los accionistas. Hacia 1775 algunos accionistas estaban dispuestos a ceder sus títulos si se los pagaban a un $33 \%$ de su valor nominal.

El último paño que se puso en el telar, de los que se construyeron por esta Real Compañía, fue el 26 de marzo de 1779; de manera que desde el 29 de marzo de 1763 en que se puso el primero, hasta este último que hemos indicado, se construyeron 1320 paños y 16 ratinas, o sea, 1336 piezas con 14.794 ramos y medio. También se fabricaron algunas sargas y estameñas aunque en corto número. Saliendo cada pieza a unos 11 ramos, que a razón de 33 varas poco más o menos, componen un total de 44088 varas, es decir, unas 2755 varas al año, saliendo por término medio cada año a 83 paños de 33 varas cada uno ${ }^{24}$.

La situación financiera de la fábrica el 16 de mayo de 1777 era la siguiente: la cantidad aportada por los accionistas era de 578.500 rs.; como el valor de la casa y el utillaje ascendía a 191.081 rs.; el de la lana , a 21.044 rs. y 21 mrs.; hilazas, simples, etc., a 46.891 rs. y 32 mrs.; paños acabados no vendidos, a 143.858 rs. y $20 \mathrm{mrs}$; y las deudas a favor 95.625 rs. y $7 \mathrm{mrs}$., o sea que, el total de las existencias de capital invertido o disponible, ascendían a $498.528 \mathrm{rs}$. con $12 \mathrm{mrs}$., lo que quiere decir que se llegaba a un alcance de menos 79.971 rs. y $22 \mathrm{mrs}$.

Se ve claro que la dificultad de colocar en el mercado los paños y, en definitiva, de realizar la mercancía, determinaba la inmovilización de capi-

$24 \quad$ Ibidem, p. 405. 
tal. Este estado queda demostrado por las "deudas a favor" que representaban el valor de paños servidos a los comerciantes, pero no pagados a la fábrica, lo que representaba un $48 \%$ del capital invertido o disponible. Ésta y no otra fue la verdadera causa del fracaso de esta empresa. Por Real Orden de 15 de marzo de 1779, se estableció la extinción de la Compañía y se mandó vender en pública subasta todas sus pertenencias, para resarcir en lo posible a los accionistas.

El fracaso fue encubierto por la administración real bajo la excusa de que «el privilegio privativo de fabricar paños superfinos, es perjudicial a los demás fabricantes $y$, por consiguiente, a las manufacturas» 25.

Por un cálculo efectuado por el director de maniobras de la fábrica, Juan Pedro Fay, en el que se pormenorizaba el valor de todas las operaciones necesarias para la elaboración de un paño, se llega a la conclusión de que el costo de fabricación de un paño llegaba a 1.818 rs. y $23 \mathrm{mrs}$. Si cada paño tenía aproximadamente unas 35 varas, $y$ vendido en piezas salía a 57 rs. cada vara, daba un total de 1995 rs. el precio de venta de un paño. De lo que se deduce, que la ganancia en cada unidad fabricada ascendía a 176 rs. y $11 \mathrm{mrs}$. Por esta cuenta sale, que si la Compañía hubiera tenido en pleno rendimiento los 20 telares proyectados, trabajando unas 12 piezas al año cada uno, se fabricarían un total de 140 piezas, lo que daría unos 42.317 rs. y 22 mrs. de rendimiento al año ${ }^{26}$.

De haber salido asi las cosas no cabe duda que hubiera sido un negocio floreciente, pero la multitud de factores negativos que hemos visto a lo largo de estas páginas llevaron al traste a la Real Fábrica de paños superfinos de la Compañía.

Un mes y medio antes de la disolución de la Real Fábrica, dos fabricantes segovianos, D. José Manuel Ramiro y D. Laureano Ortiz de Paz, propusieron a Carlos III establecer una nueva manufactura en régimen de compañía. Se comprometían a producir de 800 a 1000 paños anuales, pero ponían una serie de condiciones, que reflejaban una mentalidad marcadamente antiordenancista, respecto a la producción. Solicitaban poder fabricar cualquier tipo de paños, con las clases de lanas que juzgasen más a propósito; utilizar el utillaje más adecuado; gozar de diversas franquicias en la venta de los paños y compra de simples; que ninguna persona o entidad pudiera inspeccionar su producción, y la facultad del tanteo de las lanas. El rey aprobó esta propuesta, pero la Junta de Comercio ale-

25 larruga, Eugenio, op. cit, p. 261.

26 ibidem, pp. 259-260. 
gando que la concesión de dichas gracias y mercedes a dos particulares fabricantes podría perjudicar a los demás y alterar el orden establecido, elevó una serie de reparos, de inspiración conservadora, que terminaron con esta nueva iniciativa.

Pero en este tiempo salió a subasta la Fábrica de la Compañía y D. Laureano Ortiz de Paz, sin la compañía de D. José Ramiro, decidió pujar en ella.

El día 15 de abril de 1779, se anunció en los puestos públicos la tasación y venta en subasta de los efectos de la Compañía. La casa se valuó en 135.735 rs. y sus efectos, en 425.209 rs. y 16 mrs. La proposición de D. Laureano Ortiz de Paz fue de 289.950 rs. en efectivo y al contado, que era la mitad de los 578.500 rs. del fondo puesto por los accionistas ${ }^{27}$.

\section{FÁBRICA REAL DE PAÑOS DE ORTIZ DE PAZ}

Viendo D. Laureano Ortiz de Paz que en Segovia había un gran número de desocupados que vagaban por las calles y plazas, decidió emplear sus caudales con el fin de que los pobres estuviesen ocupados y ganasen el sustento honestamente, siendo útiles al Estado. Por esta razón decidió invertir su capital en la compra de la fenecida Real Compañía de paños superfinos.

La escritura de venta ${ }^{28}$ se formalizó el día 22 de octubre de 1779 , ante escribano público y en presencia de D. Juan de Ochoa, Intendente de la ciudad, y cuatro vecinos de Segovia, comisarios y apoderados para el efecto: D. Diego Antonio Robledo, D. Juan Gervasio Ramiro, D. Manuel Pardo de Figueroa y D. José Álvaro Rosuero.

Antes de la firma de la escritura de venta, se sucedieron una serie de reuniones encaminadas a tomar los acuerdos necesarios para proceder a la extinción de la Compañía.

Vistos los malos resultados y que la decadencia de la Compañía era imparable, se celebró junta de accionistas, el día 10 de octubre de 1778, para que se tuviese conocimiento de lo resuelto y votado en la junta de vocales, sobre las proposiciones que habian hecho dos accionistas en relación con los posibles remedios a tomar. El día 26 de enero de 1779 se ce-

\footnotetext{
27 AMS, Lainez, Marcelo, Revista de la Sociedad Económica Segoviana de Amigos del País Año III, núm. 8, 14 de junio de 1878.

28 AHP, Protocolo núm. 3012 , folios 539 y ss.
} 
lebró junta general en la que se dio a conocer una Real Orden, en donde se prevenía de los efectos negativos que estaba produciendo en la fábrica común, la exclusividad de fabricar paños superfinos por parte de la Compañía, por lo que se proponía la conveniencia de vender en pública subasta los efectos existentes, repartiendo a prorrata su producto, o enajenar sus acciones, recibiendo en dinero la tercera parte del capital invertido, ya que S. M. Estaba desengañado « de que no podia tener adelantamiento la Compañía, ni con su subsistencia las fábricas de esta ciudad". Todos los concurrentes a favor de la pública subasta.

El 7 de febrero se celebró otra junta general ya que se había recibido una carta del rey, en la que se decía que: "Se hechava de menos que no se huviese tomado en consideración, la necesidad de dar ocupación a los operarios, sin intermisión para mantener a sus familias",en consecuencia se ordenaba que se tuviese en cuenta el beneficio de los operarios. Una vez superados estos problemas, mandó S. M. que se vendiesen en pública subasta todos los enseres y efectos de la Compañía, y que se repartiese su producto entre los interesados, en proporción de los capitales invertidos en sus acciones. El propio monarca sujetaba a esa regla el caudal invertido en ella.

Una vez que la extinción de la Compañía y la venta de sus enseres -en lo que el rey estaba de acuerdo - no causaba atraso ni perjuicio en la ocupación de los operarios empleados en ella, se tomó la resolución de finiquitar la Compañía. Anulado el privilegio que gozaba de labrar ella sola los paños superfinos, quedaban en libertad de hacerlo los fabricantes particulares de la ciudad y en disposición de encontrar el premio que mereciera su industria y su aplicación.

Se ordenó a los directores tomar razón de los enseres y tasación de ellos, nombrando depositario a Juan Pedro Fay, maestro de maniobras de la Compañía. Se nombró a D. Manuel Pardo y a D. José Álvaro para acompañar a los directores, y el 14 de abril, se celebró junta de accionistas en la que se hizo saber el estado e inventario de los efectos y sus valores. Acto seguido, se nombraron apoderados para que en nombre de todos vendieran por mayor o por menor, o como mejor pudiesen, todos los efectos. Como eran lanas, hilazas, jergas, paños, utensilios, materiales y casa.

Se nombraron como tasadores a personas imparciales e inteligentes en las respectivas materias:

- Para la casa principal y accesorias, a Antonio de Torre, maestro arquitecto.

- Para el maderaje, a Juan Herranz, veedor de los oficios de carpintería y albañilería. 
Real Fábrica de Paños Superfinos de la Compañia y Fábrica Real de Paños...

- Para el hierro perteneciente al tinte y otras oficinas, a José Gutiérrez, maestro herrero y cerrajero.

- Para las tijeras de tundir, a Tomás Gutiérrez, maestro esmolador.

- Para las calderas del tinte, a Francisco Pardo, maestro calderero.

- Para los palmares de la tienda de la percha, a José Arroyo.

- Para el vidrieraje, a Tomás Gutiérrez, maestro vidriero.

- En cuanto a las lanas blancas teñidas, hilazas, tramas, jergas, paños rematados, los existentes en el almacén, materiales y demás utensilios, se tasó y estimó con intervención de los comisarios y apoderados y D. Laureano Ortiz de Paz, con atención a los precios corrientes que la Real Compañía los había comprado y costeado.

El día 15 de abril de 1779 , se pusieron carteles en los puntos públicos de la ciudad, para hacer saber a todos la subasta. Previniendo: que las posturas se admitirían hasta el día 26 del mismo, en horarios de diez a doce de la mañana y de cuatro a seis de la tarde, en la contaduría de la Fábrica. El día 19, presentó pliego D. Laureano Ortiz de Paz, ofreciendo 250.000 rs. de vellón, y se consideró inadmisible por parte de los comisarios y apoderados. El día 24 del mismo mes, se presentó el mismo don Laureano, e hizo proposición de tomar dichos efectos que ascendían a 425.209 rs. y $10 \mathrm{mrs}$., por la cantidad de 289.250 rs. en efectivo y de una sola paga, quedando a beneficio suyo las deudas a los operarios, que durante el proceso de venta habían seguido trabajando y ascendieron a 3.403 rs.

Por fin, el día 4 de mayo, después de cumplido el plazo de nueve días concedido, ante el Sr. Intendente y los diputados y comisarios, a las doce del mediodía "se pasó a encender el cabo de una vela según costumbre" y D. José Ortiz de Paz, primo de don Laureano y en nombre de éste, validó el pliego que tenía presentado para tomar los efectos de la Compañía. No habiéndose presentado ningún otro postor, fue admitida esta propuesta "finalizado y consumido que fue enteramente el cabo que para hacer dicho remate se había encendido". Todo lo cual se ejecutó a puerta abierta y en pública subasta.

\section{A) Tasación, inventario y entrega de enseres}

Estando presente el Sr. Intendente, D. Juan de Ochoa; los directores D. Diego Antonio Robledo y D. Juan Gervasio Ramiro; y D. Manuel Pardo de Figueroa y D. José Álvaro, apoderados nombrados al efecto, usando de 
la facultad conferida y otorgada, se procedió a la tasación y venta de los distintos efectos de la Compañía.

La casa denominada "Grande" y tres casitas que se hallaban lineales a ella, sitas en esta ciudad en la feligresía de Santa Eulalia, en el Campillo que dicen de San Antonio el Real, cuya extensión total era de 64.165 pies superficiales, es decir, $4.994,6$ metros cuadrados ${ }^{29}$, tasado todo ello en la cantidad de 135.735 rs. de vellón libre de cargas, excepto la merced de aguas a pagar anualmente a la ciudad.

También se vendieron a D. Laureano Ortiz de Paz todos los enseres y le fueron rematadas las lanas teñidas y sin teñir de diferentes clases, tinturas, hilazas, tramas, jergas, paños rematados, otros en el almacén, ratinas, materiales, utensilios y deudas a favor de la Compañía. Todo ello le fue entregado el día 17 de mayo.

El inventario ascendió a 419.039 rs. y 14 mrs., más las deudas a los operarios que ascendieron a 3.403 rs.; todo ello por precio y cuantía de 283.069 rs. y $32 \mathrm{mrs}$., pues aunque la postura era de $289.250 \mathrm{rs}$., se bajaron 6.170 rs. y 2 mrs., los mismos que faltaron del valor de la primera tasación hecha en enero, que había sumado 425.209 rs. y $16 \mathrm{mrs}$. Por haber sido condición en el contrato, que si se subiese o bajase alguna cantidad cuando se hiciese la entrega - por causa de seguir trabajando los operarios-, se habia de subir o de bajar mutuamente el exceso que hubiese sido.

La cantidad total fue pagada en monedas del siguiente modo: 156.560 rs., en 7.928 pesos fuertes de plata de 20 rs. de vellón cada uno; 124.480 rs., en 389 doblones de a ocho, siendo el valor de cada uno 320 rs. de veIlón; 30 rs., en una moneda de peso y medio fuerte de palta, y, por último, 9 rs. y 32 mrs., en plata menuda y vellón.

La compra fue eximida de pagar a la Administración de Rentas Provinciales, los derechos de alcabalas y cientos que correspondian a $S$. M., pues así lo decía una Real Orden en la que se especificaba que "... no debian cobrarse estos derechos, por estar incluidos en la franquicia concedida a la Fábrica de la Compañía y por ser el rey interesado y especial protector de ella (...) por lo que ni los vendedores ni el comprador,

29 En el Archivo Municipal de Segovia, en el núm. 4 de la Revista de la Sociedad Económica Segoviana de Amigos del Pais aparece publicada una "tabla de equivalencia" entre las medidas superficiales métricas y las medidas antiguas usadas en Castilla. Según esta tabla, siendo una vara segoviana igual a $0,837 \mathrm{~m}$., el pie sería igual a 0,279 m., y el palmo 0,20925 m. Por tanto, un palmo cuadrado seria igual a $0,0437855625 \mathrm{~m}^{2}$; ; un pie cuadrado $0.077841 \mathrm{~m}^{2}$, y una vara cuadrada $0,700569 \mathrm{~m}^{2}$. 
tienen que pagar por esta enajenación derechos algunos de cientos y alcabalas".

a. 1. La casa.-Fue valorada por Antonio de Torre, maestro de obras y arquitecto de la Catedral y obispado. La Casa Grande constaba de 118 pies de largo, 38 de ancho y 37 de alto, es decir, $32,9 \mathrm{~m}$. de largo, por $10,6 \mathrm{~m}$. de ancho y 10,3 m. de alto; compuesta de tres cuerpos en los que se distribuían sus habitaciones. En la planta baja estaba el portal, la contaduría, un almacén de lanas, un cuartito para las hilazas y espinzadero, un dormitorio y una cocina. En la primera planta se encontraba una oficina de telares, otras de emborrar, una antesala, dos almacenes para paños, un dormitorio, un camarín y otro cuarto. $Y$ en el último cuerpo, se componía, sólo en la mitad de su línea, de un corredor y diferentes cuartos.

También tenía la oficina de prensa con su cuarto de encartonar, cocinilla y otros cuartos encima y se extendía su línea 58 pies de largo $(16,1$ $\mathrm{m}$.) por 48 de ancho (13,3 m.), incluyendo en esta medida un jardincillo de 27 pies de largo $(7,5 \mathrm{~m}$.) por 29 de ancho $(8 \mathrm{~m}$.).

Asimismo, tenía la oficina nueva - que se hizo por cuenta de la Compañía- para los telares, 141 pies de largo (39,3 m.), por 100,5 de ancho (28 m.) y 11 de alto $(3 \mathrm{~m}$.), con un cercado de las mismas dimensiones.

La oficina de tinte de nueva fábrica, con sus hornos y chimeneas, todo ello solado de cantería, tenía 43 pies de ancho (11,9 m.), por 58 de largo $(16,1 \mathrm{~m}$.) y 18 de alto $(5 \mathrm{~m}$.). Un lavadero solado de cantería medía 14,5 pies de ancho $(4 \mathrm{~m}$.), por 28,5 de largo $(7,9 \mathrm{~m}$.). Lana lberca constaba de 41 pies de largo $(11,4 \mathrm{~m}$.), por 28 pies de ancho $(7,7 \mathrm{~m}$.), y su fábrica era de cantería, como el subiente y los canales para surtir las calderas. Todo ello en piedra berroqueña, nuevo y bien construido.

Igualmente contaba con un colgadizo muy arruinado con unas oficinas anejas, cuyas medidas eran 176 pies de largo $(49,1 \mathrm{~m}$.), por 25 pies de ancho $(6,9 \mathrm{~m}$.). Entre el colgadizo y las oficinas había una cerca de 156 pies de largo (43.5 m.) y 123 de ancho $(34,3 \mathrm{~m}$.).

También tenía un corredor de 152 pies de largo $(42,4 \mathrm{~m}$.), por 28,5 pies de ancho $(7,9 \mathrm{~m}$.) y 28 pies de altura $(7,7 \mathrm{~m}$.), formado por tres cuerpos, donde se encontraban las oficinas de lonja; y en los sótanos, la sala de tundidores y perchas, con diferentes cuartos, todo ello en mal estado.

La Casa Grande había pertenecido a Francisco de Vinatea Mercader y Beatriz de Orduña, su mujer, que la vendieron, el 29 de julio de 1572, al canónigo de la catedral de Segovia, D. Juan de Contreras, por 1.000.000 de mrs. Estaba gravada con $43.000 \mathrm{mrs}$. de censo, que se debía a dicho 
canónigo; $1000 \mathrm{mrs}$. de censo, que tenía la ciudad sobre la merced de agua que poseía dicha casa, más otros dos: uno de $32,5 \mathrm{rs}$. anuales, que el monasterio de San Antonio el Real, tenía sobre una de las casas accesorias y el otro, por valor de una libra y tres cuarterones de cera, para las Tinieblas de cada año, a favor de la iglesia de Hontoria.

En 1635 heredó la posesión D. Luis de Contreras Girón, marqués de Lozoya, hijo de Juan de Contreras, nieto del canónigo Juan de Contreras, y la transfirió en venta a Tomás Meléndez, con la merced de agua de la "Puente Seca» ${ }^{30}$ de esta ciudad y un censo perpetuo de $1.400 \mathrm{mrs}$. cada año, sobre las casas accesorias que tenían las religiosas de San Antonio el Real. Por no reunir buenas condiciones para la vivienda de D. Luis de Contreras, ya que estaba alejada del comercio de la población, se pidió permiso real para enajenarlas del mayorazgo, al servir más a la ruina de éste que a su acrecentamiento. Fueron vendidas a censo y tasadas en 26.400 rs. que componían el principal, y se hacía cargo de los censos que gravaban la propiedad., demás de otro anual de $1.320 \mathrm{rs}$. al mayorazgo de D. Luis de Contreras, que era lo que subían los réditos anuales del principal de 26.400 rs., al $5 \%$ de interés.

Como se debían 12.540 rs. de los réditos del censo de los últimos 9 años, en 1.691 se hipotecaron las casas y se sentenció la causa de remate en 40.000 rs. Fueron sacadas a la venta $n$ ese mismo año y las compró D. Juan Alfonso de Malpartida Altamirano, en 48.800 rs. Éste retrocedió el remate en Pedro Meléndez Gonzáles, regidor de Segovia, nieto de Pedro Meléndez Ayones, pues había pagado las deudas y se había comprometido a redimir el censo de 26.400 rs., que tenía la casa con el mayorazgo del Marqués de Lozoya.

En 1763 Félix Antonio Meléndez Ayones y Reinoso, regidor de Segovia, debía los réditos de varios años atrasados del censo al Marqués de Lozoya, lo que subía a 7.524 rs. Se embargaron las casas y se sacaron a la venta, por lo que D. Manuel Hernández Merino, D. Félix Herranz, D. Manuel González de Lozoya y D. Manuel Gutiérrez, diputados de la antigua fábrica de paños de Segovia y comisarios de la Real Compañia, hicieron postura en 39.200 rs. libres de toda carga; Félix Meléndez se comprometía a redimir el censo de 26.400 rs. al Marqués de Lozoya y los 8000 rs. que se debían de los atrasos, que fuerorı pagados por dicha persona. $1 \mathrm{~m}$ portaban ambas partidas 34.400 rs. Como el precio tasado había sido de

3n Nombre con el que se ha conocido al Acueducto en Segovia y así aparece denominado en múltiples documentos antiguos. 
Real Fábrica de Paños Superfinos de la Compañía y Fábrica Real de Paños...

39.200 rs., uedaba de resto y superávit 4.800 rs. pertenecientes al mayorazgo que había fundado Pedro Meléndez Ayones y fueron entregados a don Félix.

Habiendo reparado que dicha cantidad legítimamente no le correspondía a Félix Meléndez, por ser capital y efecto privativo como sobrante del precio y pertenecer al mayorazgo, se entregó a los herederos del mismo por parte de Ortiz de Paz, en un plazo de 8 años, pagando 600 rs. cada año, a la Depositaría general de la ciudad.

a. 2. El maderaje.-El maestro de carpintería, Juan Herranz, realizó la tasación correspondiente a todos los elementos de madera, que se encontraban en las distintas dependencias de la fábrica, separándolos de otros materiales, es decir, al tasar la prensa de los paños, por ejemplo, solamente valoró la estructura de madera, sin incluir las partes metálicas como el husillo o las planchas. Se fueron enumerando y tasando todas las piezas de madera en las distintas oficinas de la fábrica: oficina del tinte, de la percha, de la prensa, de los tundidores, cuarto del remiro, la de despinzar, la de urdir, el almacén de hilazas, la contaduría, almacén de paños, oficina del potro, de los tejedores de arriba, de los tejedores de abajo y la lonja.

La mayoria de estos elementos eran muy simples: borriquetas; tableros de distintas dimensiones, algunos de ellos forrados con mantas y lienzos, como era el caso de los que se encontraban en la oficina de los tundidores; cierto número de «bayartes» - artefactos formados con dos varas gruesas con unas tablas atravesadas, en las que se colocaba la carga para llevarla entre dos personas-; distintos "tinacos", es decir, tinajas de madera pequeñas; bancos alargados; mesas de diferentes tamaños para espinzar o para el remiro; "la rambla" - artefacto compuesto de postes de madera fijos verticalmente en el suelo y unidos por dos series de travesaños, con puntas o ganchos de hierro en que se colocaban los paños para enramblarlos-; la armadura de la prensa; diferentes asnillos; diversas estanterías y escaleras para acceder a ellas; "un zarzo" -especie de tejido hecho de mimbres; y varios telares. Los precios de todos estos elementos eran muy variados, pues dependían de sus dimensiones, pero entre los más caros podemos incluir una tina, cuyo valor era de 380 rs.; la armadura de la prensa, 800 rs.; o los telares, cuyo valor oscilaba entre los 300 rs.

Como se puede observar se trata de artilugios sencillos y artesanales. No se describe ninguna máquina complicada, por lo que el valor final del maderaje no significaba una gran inversión, pues ascendía a $10.495 \mathrm{rs}$. y $16 \mathrm{mrs}$. 
a. 3. El hierro. - La tasación de hierro fue hecha por José Gutiérrez, maestro de herrería, que tampoco describe complicadas máquinas. Todo ello consistía en herramientas sencillas como pueden ser diferentes "garabatos", es decir, una especie de ganchos para mover la ropa en las tinas del tinte; varios pesos y romanas con sus pesas; las lanzaderas de los telares; varias barras y palancas; las planchas de la prensa y los morillos para poder calentarlas en la caldera; cuchillos de desborrar y un relámpago para la lumbre (suponemos que esto último será un mechero de pedernal para encender la lumbre). Lo más caro eran las plancha de la prensa que ascendian a 881 rs., y el total de la tasación del hierro a 2.196 rs.

a. 4. Tijeras de "esmolar" (afilar).-El maestro "esmolador", aunque podía descender el valor de las mismas según su función dio relación de 17 tijeras barcelonesas. El precio normal de cada una debía de ser de $400 \mathrm{rs}$. El total ascendía a $5.974 \mathrm{rs}$., incluyendo $384 \mathrm{rs}$. del plomo que se usaba para cargar las tijeras.

Refiriéndose a la simpleza de la maquinaria utilizada en Segovia, Larruga nos relata el ejemplo de un herrero llamado Bartolomé Janer, hombre habilidoso y capaz para hacer cualquier cosa, que se hizo maestro de "esmolar» tijeras. Su trabajo, unas veces bien y otras mal, el caso es que daba satisfacción a los segovianos, «bien que estos se contentan con poco, pues sus herramientas son tan simples, que con poca reflexión de maestro, podrá pasar por tal, qualquiera que se dedique a esta facultad» ${ }^{31}$.

a. 5. Calderas de tinte.- - Sin embargo, lo que síllama la atención por su precio, en relación a lo que hemos visto hasta ahora, son las diferentes calderas. Según la tasación efectuada por el maestro calderero Francisco Prado, una caldera grande de teñir paños negros de 22 arrobas, ascendía a 3.850 rs.; una caldera de teñir lana , 3.375 rs.; una de cobre, 3.144 rs., y otra de azófar 1.963 rs. El total de esta tasación sumaba 12.104 rs. y 8 mrs.

a. 6. Palmares. - La tasación de los palmares en la tienda de percha inglesa, efectuada por el maestro de cardar José Arroyo, ascendía a 1.820 rs., siendo el precio aproximado de cada uno de ellos, de unos 300 rs. más o menos, según su tamaño.

a. 7. El vidrio. - La tasación del vidrio, es decir, los cristales de todas las puertas y ventanas del edificio era de 7.220 rs.

31 Larruga, Eugenio, op. cit, p. 200. 
Si hasta aquí hemos visto el inventario de los elementos de hierro, madera, vidrio y algunas herramientas, a continuación se va a enumerar el de la materia prima, los distintos simples o materiales de tinte, el de los paños y el de algunos utensilios. En esta parte del inventario se detalla en primer lugar el producto de que se trata, la cantidad en arrobas y libras, el precio por arroba y su valor total

a. 8. La lana.-Al describir las existencias de lana se hace relación de las diferentes calidades. Lana relavada y medio desmote, a $250 \mathrm{rs}$. la arroba; lana de primer lavaje y medio desmote, a 185 rs. la arroba; peladas de primer lavaje y medio desmote, a 180 rs.; orillas en lana sin repasar, a 60 rs.; lana parda basta lavada, a 60 rs., etc. El total de lanas ascendía a 20 335 rs. y 2 mrs.

Si el párrafo anterior nos ayuda a hacernos una idea de los precios de la lana, a continuación vamos a ver los diferentes colores que se empleaban y sus correspondientes precios. Al hacer la relación de "hilaza bervi» o de «tramas», se mencionan los colores azul, color caña, color de castaña, blanco, perla, de oro, de carne y de oblea. El valor de estos productos oscilaba entre los 18 y $19 \mathrm{rs}$. la arroba, siendo el valor del total almacenado de 22.788 rs. y $16 \mathrm{mrs}$.

a. 9. Jergas y paños.-A la hora de inventariar las jergas y los paños, se detalla el número de ramos, el de varas, el precio por vara y el precio total de la pieza. Los ramos suelen oscilar entre 10 y 12; cada ramo tiene 4 varas, lo que hace que los diferentes paños o jergas oscilen entre las 40 y 48 varas la pieza, es decir, entre $33,4 \mathrm{~m}$. y $40,1 \mathrm{~m}$. También variaba el precio según el color y la calidad. Por ejemplo, una jerga de color azul, $30^{\mathrm{eno}}$, de 12 ramos, 48 varas $(40,1 \mathrm{~m}$.), a $28 \mathrm{rs}$. la vara, tenía un valor total de 1.344 rs.; otra jerga igual pero $34^{\text {eno }}$, salía a 30 rs. la vara y el total a 1.440 rs. la pieza. Los paños rematados eran un poco más caros, pues un paño negro $30^{\text {eno }}$, de 12 ramos de 38 varas y $1 / 4$ (32 m.), a $53 \mathrm{rs}$. la vara, ascendía a $1.656 \mathrm{rs}$. y $8 \mathrm{mrs}$., y uno de $36^{\text {eno }}$ de 12 ramos de 28 varas $(23,4 \mathrm{~m}$.), a $63 \mathrm{rs}$. la vara, ascendía a $1.795 \mathrm{rs}$ y $18 \mathrm{mrs}$. El total de lo almacenado ascendía a 74.434 rs. y $10 \mathrm{mrs}$.

a. 10. Materiales. -Dentro de este apartado están incluidas las materias vegetales y distintos productos químicos para tinte. También se especifica la cantidad y el precio por arroba. La variedad es muy grande por lo que nos vamos a limitar a enumerar algunos de los materiales para hacernos una idea de los productos utilizados. En primer lugar aparece la 
caparrosa, a 25 rs. la arroba ${ }^{32}$; el palo amarillo, al mismo precio; el campeche, a 30 rs. la arroba; el brasil, a 3 rs. y _; la rubia, a 55 rs.; el sándalo, la agalla, el alumbre, el agua fuerte, el cristal tártaro, la sal gema, arsénico, cardenillo, cochinilla, zumaque, añil, cola, jabón y aceite, entre otros. El valor total de todos estos productos subía a la cantidad de $12.291 \mathrm{rs}$ y $6 \mathrm{mrs}$.

a. 11. Utensilios.-Aquí se menciona herramientas como las cardas, distintos peines de telares, telares, botellas para productos químicos, vasos de hacer composiciones, tamices, etc. El precio de estos productos subía a 1501 rs.

a. 12. Deudas a favor.-Por último, se da una relación de personas que mantenían deudas con la Compañía. La mayoría de ellos eran comerciantes de Segovia, aunque también figuraban algunos de Madrid y uno de Pontevedra. Las deudas sumaban 112.149 rs. y $32 \mathrm{mr}$

\section{B) Puesta en marcha de la fábrica}

La intención de D.Laureano era el restablecimiento de la Fábrica de paños superfinos, dándole aún mayor extensión de la que había tenido. Pero para ello necesitaba la protección real, por lo que recurrió a S. M., para que se le concedieran las consiguientes gracias y mercedes. Se le expidió una Real Cédula firmada en San Ildefonso el día 20 de agosto de 1779, con las gracias, facultades y exenciones contenidas en 19 capítulos, y se reducian a:

"Que pueda fabricar toda clase de paños, desde la de veintenos inclusive, hasta los más superfinos sin limitación alguna; y también mantas, bayetas, sargas y qualesquiera otros géneros de tegidos de lana, de los que vienen o vinieren de dominios extrangeros o que se fabriquen en estos reynos".

"Poder usar de todas las máquinas e instrumentos y demás utensilios para la construcción de ylazas y demás maniobras que faciliten la mayor perfección».

"Libertad de todos Ios derechos reales y municipales, en todas introducciones y entradas en Segovia, de todos los simples e ingredientes, máquinas e instrumentos, así procedentes de reynos extrangeros, como que produzcan estos reynos".

"Libertad de derechos de millones y demás que causasen en Segovia el aceyte y jabón, que se consumiere para el beneficio de toda clase de tegidos de lana, con la graduación correspondiente".

32 La arroba es la cuarta parte del quintal. Es igual a 25 libras y equivalente a $11 \mathrm{kgs}$ y y 502 g. El quintal, por tanto, contiene 100 libras o 4 arrobas y es equivalente a $46 \mathrm{kgs}$. 
"Libertad de alcabalas y cientos en las ventas de por maior y menor de los paños y demás tegidos de lana al pie de su fábrica y en las ventas y de las suertes inferiores y añinos de las partidas de lanas que no tengan aprovechamientos en ella».

"Libertad de alcabalas y cientos en las ventas de por maior y menor de los paños que se conduzcan a los puertos avilitados para el comercio libre con América".

"Exención de derechos de aduanas interiores y de los de entrada por rentas generales en los paños que se conduzcan a puertos de Cádiz, Sevilla, Puerto de Santa María y otros de Andalucía".

«Libertad de los derechos reales y municipales de los tegidos en su extracción por mar y tierra para dominios extrangeros".

"Facultad de poner almacén en Madrid por maior y menor y vareo sin pagar más derechos que el ocho por ciento a su entrada".

«Facultad de poner las armas reales sobre la puerta y almacén de la fábrica con la inscripción de Fábrica Real de Hortiz de Paz y de usar en los paños y demás tegidos el plomo que los distinga con la marca de real fábrica de los mismos apellidos, puente de Segovia y señal de sus clases y suertes".

"Facultad de poder denunciar pos si, sus factores y encargados ante las justicias, los paños y demás tegidos falsificados con la marca de su fábrica".

"Que en ella no puedan intervenir ni ejercer función alguna los veedores, sobreveedores, ni diputados de la fábrica común de Segovia, gozando en el todo de la misma independencia que gozaba la Compañia extinguida y sólo ha de estar sugeta a la inspección del intendente de Segovia".

«Que en la máquina para frisar paños y ratinas concedida por S. M., que la costeó a la fábrica de Segovia, sean preferidos los paños y ratinas de la suya, a los de otro qualquiera fabricante».

"Que pueda usar de las prensas, batanes y demás oficinas públicas de Segovia, pagando lo mismo que los demás».

"Que pueda gozar del privilegio del tanteo de las lanas conducentes a su fábrica, sobre qualquier comprador natural o extrangero que las haia comprado para revender y extraer del reyno".

"Que ha de estar exento y lo mismo su director, cagero y contador, de las cargas concejiles".

"Que los aprendices en dicha fábrica que haian adquirido la instrucción correspondiente y sido aprobados por el director de maniobras, puedan trabajar en qualquiera parte de España, en virtud de solas sus certificaciones de aprobación refrendadas con la firma de Ortiz de Paz".

"Que todas estas gracias y exenciones y las que S. M. designe concederle, han de ser subsistentes para si y sus subcesores por todo el tiempo que mantengan corriente la fábrica a lo menos con veinte telares".

"Y que goce el fuero de la Real Junta General de Comercio y Moneda" ${ }^{33}$.

33 AHP, Escritura de fundación singular, perpetua y pública vinculada. Protocolo núm, 2800 , folios 368-441. 
Animado por estos favores y beneficios, se dedicó a impulsar su empresa, ejecutó nuevas y costosas obras en la fábrica, haciendo muchas y capaces oficinas al efecto, adquiriendo gran número de aparatos y pertrechos para todas las maniobras. Estableció en la ciudad y varios pueblos de la provincia escuelas de hilazas, para ocupar operarios y perfeccionar las maniobras. Arregló y aumentó la fábrica con algunos terrenos y casas contiguas que adquirió.

A la oficina de espinzadoras le dio una amplitud capaz de acoger a 50 maniobristas, lo mismo que a la oficina de zurcidores. La lonja para lana en sucio era capaz de contener 20.000 arrobas (230.000 kgs.). Reparó dos grandes naves donde había espacio para 19 y 24 telares respectivamente. Amplió la oficina de percha donde trabajaban a la vez 40 perchadores. Añadió una prensa de nueva invención ejecutada con buen arte, de husillo perpendicular y linterna de hierro, cuyo manejo y revolución era horizontal, adaptada y fortificada con hierro suficiente como para el prensado de 8 paños a un tiempo con la mayor perfección. Habilitó una pieza pequeña, donde los tejedores preparaban la tela en un baño con agua de cola para su tejido. Además, amplió la oficina en la que se cardaban las lanas superfinas, hasta darle una capacidad suficiente para que trabajasen a la vez 100 operarios y la oficina de desmotadores era capaz de acoger a 80 personas. Acabadas las obras de la casa, viendo que no bastaba su capacidad para todo lo que había que hacer, empezó a construir otra casa conocida hoy con el nombre de «El Lagarto" cuya fachada medía 384 pies $(97 \mathrm{~m}$.) cuya superficie total, con su patio, era de 76.212 pies cuadrados ${ }^{34}\left(9.409 \mathrm{~m}^{2}\right)$.

Pero no estando conforme con el arreglo y ampliación de las instalaciones existentes, con fin de conseguir mayor eficacia, no dudó en construir un batán que cubriera todas sus necesidades, aun a costa de una gran inversión. Con estas miras elevó un memorial ${ }^{35}$ al Ayuntamiento, el 11 de diciembre de 1779 , en el que, tras explicar los motivos que le habían impulsado a adquirir la fábrica de la Compañía y a acometer las obras de ampliación realizadas en ella, se exponia la necesidad de construir un nuevo batán que permitiera mantener la higiene necesaria para la manufactura del elevado número de paños al que ascendería la demanda, a partir de la puesta en marcha de los 50 o más telares que pensaba instalar en su fábrica.

Aunque el capítulo 14 de las reales concesiones le permitía el uso de los batanes, que desde antiguo estaban construidos para el uso de la fá-

34 Ibidem.

35 AMS, Libros de Actas. Sesión del sábado día 11-12-1779. 
brica común sobre el río Eresma, se daba la circunstancia de que estos eran insuficientes para poder atender la demanda del resto de fabricante.

El ánimo de Ortiz de Paz era no crear inconvenientes a los demás fabricantes, pues la legada de sus paños a los batanes retrasaría la entrega de los suyos al resto de fabricantes. Pero además había una exigencia de origen técnico, y no era otra que, al ser la producción de su fábrica de paños superfinos, estos necesitaban un mejor acabado y, por consiguiente, un mayor empleo de tiempo para su limpieza.

Don Laureano eligió como lugar más idóneo para construir su batán el que mejor y más cómodo le venía para su fábrica:

«... y no hallando otro sitio más cómodo no proporcionado que contiguo del que lo está a la casa de la Retina, cuia máquina se muebe y gobierna con las aguas que conduce la cacera para el abasto común desta ciudad y hasta aora no se ha bisto seguirse el menor perjuicio en las aguas, porque tan puras como entran salen y de la misma forma y con el mismo método han de entrar y salir en el batán como así lo demuestra el plan formado y que exibe a $V$. S... ${ }^{36}$.

El memorial iba acompañado de los planos y dibujos correspondientes, incluso iba adjuntaba una maqueta de madera, donde quedaban especificadas todas las características del nuevo batán.

«...para la construzión del batán que solicita inmediato a la casa Ratina, ha hecho hacer en madera el modelo correspondiente, el qual presenta a $\checkmark$. S. para que más bien si fuere de su agrado, se enteren todos los señores individuos del M. N. Ayuntamiento de la máquina, entrada y salida de las aguas de la cacera y la que se está solicitada por merced para la pila y mazos de batán" ${ }^{37}$.

Según el proyecto presentado por Ortiz de Paz, la pureza de las aguas no se vería perjudicada, pues solamente se utilizaba para mover la rueda que ponía en funcionamiento la maquinaria. Para la limpieza de los paños solicitaba "un real de agua poco más o menos» y ésta, desde luego se perdería al quedar impura, y sería evacuada al arroyo inmediato de aguas perdidas, es decir, al arroyo Clamores, que pasaba por delante de la fábrica y de ningún modo podría entrar en la cacera principal. Indudablemente, en lo que toca a la merced del real de agua para limpieza, estaba dispuesto a pagar por ello anualmente, la misma cantidad que cualquier

\footnotetext{
36 Ibidem.

37 Ibidem.
} 
cerbatana y merced de agua para tinte y fábrica pagase, o lo que fuere del agrado del Ayuntamiento.

Utilizar la cacera del Acueducto para el movimiento de una máquina podría entrañar una serie de riesgos que el Ayuntamiento no estaba dispuesto a consentir.

El señor Torres, uno de los regidores, se oponía a la construcción de dicha máquina, porque «eran muchas las contingencias que en un futuro se podrían originar". Tantas que no era posible tenerlas todas previstas. Una de ellas y la más inmediata, eran los malos olores que producirían la mugre de los orines, aceite, jabón y otros ingredientes necesarios para la limpieza de los paños.

"Y asimismo el vertiente y salida de estas aguas puercas, teniendo que atravesar toda la Dehesa y unirse con el arroyo que bierie por devaxo del puente de Baldebilla y sirbe hasta la parrochia de Santa Eulalia, para el uso de lavar la ropa a todos aquellos barrios, de que quedarán privados desde donde vierten estas aguas puercas impidiendo bever a los ganados" ${ }^{38}$.

Por su parte, D. Laureano estaba dispuesto a destruir dicha obra y dejarlo todo como estaba si ésta llegaba a ocasionar un perjuicio imprevisto. El señor Torres se hacía cargo de la buena fe del peticionario, pero en su opinión era muy violento exponer una obra de tanto coste a esta ontingencia.

Con respecto a la merced de medio real de agua, la opinión de Torres era que una vez construido el batán y no siendo suficiente esta cantidad, se tendría que dar cualquier incremento en el consumo, con el consiguiente perjuicio para el resto de los vecinos, que se verían perjudicados en el abastecimiento de agua potable para el consumo.

“... a quien Dios N. S. y la naturaleza la dotó (a la ciudad) de unas aguas tan puras, christalinas y abundantes, de que es envidiada de todas o las más ciudades del reino y por su puente conocido en todos los reinos, que sin ellas sería su vecindario el más infeliz y desdichado" ${ }^{39}$.

Además de todas estas razones aludidas para oponerse a la construcción de un batán, aprovechando el agua de la cacera del Acueducto, terminaba diciendo que estaba prohibido por las ordenanzas. Pero cono- 
ciendo el beneficio que recibía Segovia con la instalación de tan gran fábrica de paños, no le cabía duda de que la ciudad le concedería graciosamente en cualquier paraje del río Eresma, el sitio que más se acomodara para dicha obra; además de contribuir con 30 ó 40 pinos de Valsaín, para facilitarle la construcción de la misma.

Las ordenanzas a las que se hace referencia son las que regulaban el consumo del agua y la conservación de la cacera para su perfecto abastecimiento. Dichas ordenanzas databan del reinado de D. ${ }^{a}$ Juana, en el año 1505 , y en ellas se prohibía construir "molino ni otro artefacto en la mencionada cacera" desde donde nacía el agua hasta donde entraba en la ciudad, ni tampoco dentro de ella.

Las declaraciones del resto de los regidores son muy similares, excepto la de uno que no veía mal en ellos y, por tanto, no se oponía a la construcción del batán. Como la mayoría no estaba de acuerdo, no se le concedió licencia para construir dicha obra, pero sí se le dieron todas las facilidades para hacerlo en el río Eresma.

El lugar elegido fue en la ribera del río junto a "el último batán», a medio cuarto de legua del molino del Marqués de Lozoya y por encima del camino de Tabanera. Para ello empleó más de 30.000 ducados en la construcción de la nueva presa, caja y casa.

La casa de habitación era de unas dimensiones de 58 pies en cuadro (16,1 m.) y se componía de sala, dos cuartos, cocina y cuadra. La presa tenía 100 pies de largo $(27,9 \mathrm{~m}$.), por 13 pies de grueso $(3,6 \mathrm{~m}$.) y 16 pies de alto $(4,4 \mathrm{~m}$.). Hecha de mampostería y cubierta de losas de cantería y piedra cardena con grapas de hierro, disponía además de las correspondientes compuertas. Se acompañaba esta presa, con las construcción de un cazo para tomar el agua del río y conducirla a la máquina de 30 pies de largo ( $8,3 \mathrm{~m}$.), por 9 pies de ancho (2,5 m.), enlosado de la misma cantería y sus paredes con el grueso de 4 pies $(1,1 \mathrm{~m}$.). La caja de la máquina se componía de cuatro pilas con sus ruedas y canales y sus correspondientes entradas de agua también hechas de cantería. Además había otro caz de 200 pies de largo $(55,8 \mathrm{~m}$.), por 8 pies de ancho $(2,2 \mathrm{~m}$.) y 4,5 de grueso $(1,2 \mathrm{~m}$.), por donde se dirigían las aguas salientes desde la máquina hasta el río ${ }^{40}$.

En todas estas obras y compras de utensilios, la de la casa primitiva y terrenos adyacentes, gastó 2.300 .000 rs., llegando a tener por entonces corrientes 70 telares dentro y fuera de la fábrica, con 80 escuelas de hila-

40 AHP, Escritura de fundación singular... Protocolo núm, 2800, fols 368-441. 
zas, manteniendo a 2800 operarios en todas sus maniobras y empleando para la conservación y marcha de esta industria 5.000.000 rs. anuales.

Esta manufactura, que se mantuvo desde 1779 a 1827, a la vista de los datos existentes hasta ahora, fue sin duda la máxima creación de la industria textil segoviana en toda su historia.

Entre 1779 y 1790 , se produjeron en este establecimiento algo más del $17 \%$ de todos los paños fabricados en la ciudad.

\begin{tabular}{rccc}
\hline Añก & FC & Año & FOP \\
\hline 1779 & 4.583 & & \\
1780 & 4.850 & & \\
1781 & 4.438 & $1779-83$ & 2.762 \\
1782 & 4.094 & & \\
1783 & 4.318 & & \\
1784 & 5.187 & 1784 & 831 \\
1785 & 5.496 & 1785 & 965 \\
1786 & 5.306 & 1786 & 947 \\
1787 & 5.050 & 1787 & 831 \\
1788 & 5.139 & 1788 & 984 \\
1789 & 5.134 & 1789 & 918 \\
1790 & 5.167 & 1790 & 678 \\
\hline TOTAL & 58.762 & & 9.006 \\
\hline
\end{tabular}

Bajo las siglas FC se indican los paños producidos por la fábrica común o resto de fabricantes; FOP se refiere a los paños producidos en la fábrica de Ortiz de Paz.

Como era de esperar, las especiales concesiones otorgadas a la manufactura de Ortiz de Paz crearon gran inquietud y malestar entre el resto de fabricantes de paños de Segovia. Gran parte de los buenos resultados que obtuvo fueron debidos a la protección de S. M. el rey Carlos III y al Excmo. Sr. Conde de Floridablanca, pese a la oposición del resto de los fabricantes. Como tenía facultades por la Real Cédula de creación de su fábrica para poder usar de las prensas, batanes y demás oficinas públicas de la fábrica común, se originaron cuestiones y pleitos.

Los diputados y apoderados de la antigua fábrica de paños solicitaron al Consejo de Castilla, el 22 de noviembre de 1780, que se derogasen las gracias concedidas a don Laureano "cuya subsistencia miraron como la raiz de su ruina", o bien que todos los fabricantes pudieran disfrutar de idénticas ventajas. Alegaban que en la fábrica de Ortiz de Paz se pagaban 
mejores jornales y en efectivo, que en la fábrica común; razón por la cual no encontraban operarios dispuestos a trabajar para ellos. Campomanes, como fiscal del Consejo, informó que no sería justo oponerse a las gracias concedidas a don Laureano, pues como podía constarle por inspección ocular de la fábrica, se trataba de un establecimiento digno de la mayor protección, por las considerables ventajas al Estado y por dar ocupación a un crecido número de familias; habiendo abierto los ojos con la mejora de sus maniobras y bondad sobresaliente de sus paños a los fabricantes antiguos, para que se estimularan y desearan imitarlos ${ }^{41}$.

Por tanto, a juicio del fiscal, no se debía de privar a Ortiz de Paz de los privilegios concedidos, sino que se debía liberar al resto de los fabricantes de las trabas de las antiguas ordenanzas.

También el corregidor de Segovia estaba a favor de don Laureano. Según él, en Segovia no había escasez de operarios para la fábrica común, sino que estos, por falta de caudales para poder soportar la continua fabricación, se veían obligados a permanecer grandes temporadas parados, hasta que disponían del producto terminado. Esta circunstancia provocaba que todos quisieran trabajar en las proximidades de las ferias, que era cuando tenían mayor salida los paños.

Queda claro entonces que la nueva fábrica pagaba mejor y al contado a sus operarios, que el resto de fabricantes. Por otra parte, la cuantía de capital con que operaba Ortiz de Paz era muy superior a la de los demás fabricantes, lo que determinaba que en ella no parase nunca la producción. Aunque no se registraron innovaciones técnicas importantes en el proceso productivo ${ }^{42}$, la concentración de capital le permitía una mayor eficacia en la utilización de los edios de producción.

Una de las características sociales directamente implicadas por la concentración de los medios de producción en la industria textil urbana fue el aumento relativo del número de proletarios, es decir, los no propietarios de los medios productivos que para subsistir se veían obligados a vender su fuerza de trabajo por un salario. La mayoría de estos proletarios, procedia de los antiguos artesanos independientes, que, por falta de capital y, por

41 Garcia Sanz, Ángel, op. cit., p. 233.

42 Existen pocas noticias sobre las innovaciones técnicas producidas en el siglo XVIII en Segovia. Ya vimos anteriormente, al analizar el inventario de la extinta Compañía, que las máquinas eran muy sencillas y rudimentarias, siendo de madera la mayoría de sus elementos. Sin embargo, si se menciona una nueva máquina: la Rambla. También debía de ser una innovación la máquina para frisar los paños y ratinas y los "tornos a la holandesa" para hilar. De estas caracteristicas debía de ser la máquina de hilar que el sucesor de Ortiz de Paz, Tomás Pérez Estala, introdujo en la fábrica a poco de morir don Laureano. 
consiguiente, de competitividad, se veían obligados a cerrar sus pequeños talleres. También, otra parte de estos obreros, procedía de la inmigración campesina que se produjo -como consecuencia del aumento de la población en general- a finales del siglo XVIII.

No cabe duda de que el número de personas que intervenian en el proceso productivo del textil $-\mathrm{y}$ no eran propietarios de los medios productivos- se incrementó notablemente. En 1691 los propietarios de telares eran 173 y, sin embargo, en 1778 eran solamente 58. Pero además en esta segunda fecha era mayor la producción que en la primera. El encuadramiento de todos estos desheredados en el proceso productivo en calidad de proletarios se vio propiciado por la administración real en la segunda mitad del siglo XVIII, por la erección de hospicios cuya misión principal era la de convertir a todos estos parados, mendigos y maleantes en asalariados disciplinados y útiles para el Estado.

Para consolidar la fábrica, don Laureano se valió de las posibilidades institucionales que le brindaba la organización del Antiguo Régimen. Fundó un mayorazgo sobre su manufactura, para que la propiedad del establecimiento permaneciera indivisa y vinculada, de forma que sus herederos sólo percibirian a título individual las $4 / 5$ partes de los beneficios, puesto que se les imponía la condición de que $1 / 5$ de los beneficios habían de reinvertirse para el fomento de la fábrica. En 1787, incluso, consiguió privilegio perpetuo de nobleza mientras él y sus sucesores, estuvieran al frente del establecimiento y mantuvieran en actividad los telares.

\section{C) Fundación de mayorazgo ${ }^{43}$}

La escritura de mayorazgo se realizó en Segovia ante el escribano Tomás Fernández, el día 1 de marzo de 1786. Vinculaba todas las posesiones relativas a la fábrica, con la totalidad de enseres y materiales, dejando libres las demás casas que poseía en la ciudad, dehesas, montes de pasto y labor, ganados vacunos y lanares, labranzas y otros ramos. Dejaba cuatro herederos, tres hijos y un nieto a partes iguales; $y$ en su defecto sus descendientes, con preferencia del mayor al menor y del varón a la hembra, aunque con la salvedad de que la fábrica se debía dirigir como si fuera de una sola persona. Como el que heredaba en el mayorazgo era el hermano mayor, quedaba obligado a asistir a sus hermanos con la cuota

43 AHP, Protocolo núm. 2800, fols. 368-441. 
alimentaria hasta que estos tomasen estado. Ningún heredero podría enajenar su parte correspondiente. La dirección de la fábrica quedaría en manos del que fuese más capacitado, $y$, en caso de que ninguno poseyera la habilidad necesaria, entre los cuatro nombrarían a la persona más adecuada para ello.

Como deseaba los mayores progresos para dicha fábrica, declaraba que a todo el caudal perteneciente a la misma a la hora de su fallecimiento, se sumara la cantidad de 500.000 rs., procedentes de los demás bienes libres, para que la sociedad siguiese funcionando. Con este fin, todos los años se dividirían los beneficios en cinco partes iguales y una de ellas quedaría para el mantenimiento de la fábrica, quedando el resto para los herederos.

En caso de que alguno de los herederos quisiera deshacerse de su parte, perdería todo derecho a la propiedad, incluso hasta el alimento; porque la voluntad del otorgante era la de que permaneciera perpetua la Real Fábrica, siendo útil al Estado y en beneficio de la ciudad de Segovia. Como juez privativo conservador del mayorazgo, quedaba nombrado el Sr. Intendente general de rentas de la ciudad de Segovia.

En caso de que desapareciesen las líneas de los herederos directos, sucederían en el mayorazgo las líneas trasversales y en el caso de que también desapareciesen éstas, llamaba a la sucesión al rey confiando que se dignara admitirla.

Los herederos quedarían obligados a residir en las casas de habitación que se habian construido al efecto en la misma fábrica, con el fin de poder dirigir y vigilar mejor el manejo de la misma.

Los sucesores tendrían que ser "cristiano-católicos" y fieles vasallos del rey de España. No podrían suceder en el mayorazgo "locos o mentecatos", al igual que los clérigos de orden sacro, bien fuera monja, fraile o canónigo reglar, excepto si pertenecieren a una orden militar o de caballería.

El rey aprobó esta vinculación el día 15 de mayo de 1787, y el día 25 del mismo mes y año se expidió carta ejecutoria para que don Laureano y todos los poseedores del mayorazgo gozasen el privilegio perpetuo de nobleza, mientras mantuvieran la fábrica anexa a la vinculación ${ }^{44}$. Este privilegio original de nobleza se amplió por Carlos IV, por decreto expedido en El Escorial, el día 15 de noviembre de 1807, a D. Bartolomé Ortiz de Paz, D. Tomás Pérez Estala y D. Santiago Arranz de la Torre, el primero hijo legítimo y los otros dos hijos políticos de don Laureano. 


\section{D) El testamento ${ }^{45}$}

Don Laureano Ortiz de Paz murió el día 10 de octubre de 1788. Dejó cuatro herederos: doña Lorenza, doña Manuela y don Bartolomé, sus hijos; y D. Manuel de Bustinaga, su nieto, hijo de D. Miguel de Bustinaga y doña María, ya difunta, hija de don Laureano.

Doña Lorenza casó con D. Tomás Pérez Estala, natural de Teruel, maquinista pensionado por S. M., e Intendente honorario de provincia, en cuyo matrimonio se interesó $S$. M., con el deseo de que hubiese en la familia una persona hábil, que se pusiese al frente de la fábrica al fallecimiento de don Laureano.

En la cláusula 19 de dicho documento ordenaba una fundación perpetua de patronato real de legos y cumplimiento de misas por su alma y las de sus familiares más directos. perpetuamente. Señalaba de renta anual perpetua la cantidad de 4400 rs., que se deberían de sacar del fondo de utilidades que produjera la fábrica, antes que se repartieran entre las cuatro líneas en que se habían de dividir dichas utilidades. Se nombraban como patronos de esta fundación a las cabezas de las cuatro líneas de sus herederos.

Como tutor de sus hijos Bartolomé, Lorenza y Manuela, entonces menores de edad, nombraba a su yerno don Miguel de Bustinaga.

Para dar una idea de la importancia de los asuntos que mantenía don Laureano a la hora de su fallecimiento, resumimos los negocios y cargos que desempañaba y que figuran en su testamento:

- Comisión de factoría de lanas para las Reales Fábricas de Guadalajara.

- Comercio de paños con las Indias a través de Cádiz.

- Comercio de lanas en el norte a través de Bilbao.

- Almacén de paños en Madrid.

- Cuenta de giro de letras y compra de lanas con los señores Gobea de Madrid.

- Cabaña de ganado lanar propia y arrendada, además de varios rebaños de particulares.

45 AHP, Tomás Fernández, Protocolo, núm. 2802, 13 de septiembre de 1788. 
Real Fábrica de Paños Superfinos de la Compañia y Fábrica Real de Paños...

- Explotaba en arrendamiento los términos de Bercimuel y Serranos por 66000 reales anuales.

- Fábrica de curtidos en Segovia.

- Disfrutaba en arriendo del lavadero primero y del de la Peña, en Segovia.

- Era tesorero del fondo de expolios y vacantes y del fondo pío beneficial.

- Administraba el término de Carrascal de Gumiel.

- Tenía el abasto de carnes de la ciudad de Segovia.

- Compraba granos en Extremadura para el sostén de sus ganados, poseía varias casas en la ciudad de Segovia, tenía cuentas con varias personas, sostenía varios pleitos, etc.

Como buen hombre de negocios no dejaba nada al azar. Aunque confiaba ciegamente en sus factores y en aquellas personas que le dirigían los negocios fuera de Segovia, dejaba en su conciencia la presentación del estado de cuentas de cada uno; pero, por si acaso, dejaba claro que en su poder obraban los libros donde se especificaban todas estas cuentas.

Llaman la atención -en la lectura del testamento- las razones que va exponiendo para mantener en funcionamiento la fábrica de curtidos. Ello nos ayudará a conocer un poco la calidad humana de esta persona.

Para empezar hay que decir que fue un católico creyente y practicante, pues así lo declara en el encabezamiento de su testamento. Indudablemente, esta declaración podría tratarse de palabrería, pero creemos que no es así. Son repetidas las muestras que encontramos de sus buenos sentimientos en los distintos documentos manejados para componer este trabajo. Por ejemplo, en la escritura de compra de la Real Compañía o en la escritura de mayorazgo, al señalar las causas que le movían a la hora de comenzar la aventura de la nueva empresa, dejaba bien claro que su mayor preocupación era la de dar trabajo que permitiera el sustento a tanto desocupado. Le intranquilizaba la decadencia económica que había sufrido Segovia con el paso de los años y buscaba recuperar su antiguo esplendor industrial y comercial. Volviendo a los motivos que le movieron para mantener la fabrica de curtidos abierta, se dice textualmente en su testamento:

"Declaro tengo mía propia la fábrica y comercio de curtidos en esta ciudad y sólo la he mantenido y tengo, con el fin y objeto de favorecer a los pobres, y a que estas materias no faltasen al público; y su dirección y manejo 
le tengo puesto al cuidad de Bernardo Rodríguez, mi primo, y en este ramo quiero se esté y pase en todo y por todo, por la quenta que diere dicho mi primo Bernardo sin ponerle reparo mis herederos".

También puede observarse la confianza plena que tenía en los hombres que ocupaban puestos de responsabilidad en sus negocios. Por ejemplo, al referirse al cajero de la fábrica, José Rodríguez Reina, decía textualmente:

\footnotetext{
«... y por quanto he tenido siempre y tengo entera satisfacción y confianza en su conducta y modo de portarse, quiero y es mi voluntad que se esté y se pase en todo y por todo, por la quenta que éste diere sin que se le ponga ningún reparo».
}

En el apartado de mandas, son numerosas las que dejaba a sus familiares más humildes y a todos aquellos que habían vivido con él estrechamente, bien como criados de confianza, bien como empleados de la fábrica. La mayor parte de estas mandas eran en dinero, pero no faltaban otras en enseres de casa o en ayudas para matrimonio de las hijas de estas personas.

Las recomendaciones que daba sobre sus empleados de confianza, también son merecedoras de ser destacadas. De todos aquellos que habían ocupado puestos de responsabilidad, y él había quedado contento con su trabajo, recomendaba a sus herederos que les conservasen a cada uno en sus puestos, siempre y cuando quisieran ellos continuar. Son muchos los que tenían contraídas con él pequeñas deudas, bien por haber pedido anticipos o bien por haber empeñado algunos objetos para conseguir dinero líquido. A todos ellos les perdonaba las deudas contraídas: a su asistente, al maestro de tinte, a su amanuense, a los perchadores y tundidores, a los pelaires, emborradores, remiradores y reparadores, etc.

Como sabemos por la escritura de mayorazgo de la fábrica, destinaba una cantidad de 500.000 rs. de sus bienes libres, para el fomento de la misma. Pues bien, esta cantidad se sacaría de la venta de ganado vacuno que tenía en Ozaduero, Dehesa de Valdecuervos y Campo Azálvaro; pero de ninguna manera de la vaqueria de Bercimuel y Serranos; y lo mismo de los dernás ganados y labranzas, por las utilidades que rendian y podían rendir en beneficio de sus herederos.

Pero como los trámites hasta que se cumpliera un testamento eran lentos y la fábrica necesitaba caudales para continuar con su funcionamiento, se vio en la necesidad de pedir una hipoteca en beneficio de sus herederos para poder afrontar estos gastos. 


\begin{abstract}
"Como han sido tan crecidos los caudales que he expedido en mejorar y adelantar lo posible por todos los medios esta mi Real Fábrica, establecido escuelas en esta ciudad y pueblos de su provincia y construiendo máquinas y haciendo experimentos, no me allo con todo lo que se necesita a su maior aumento y conservación, por los muchos dineros que se necesitan, por tener que atender otros distintos ramos de consideración y de utilidad pública, por cuia razón con toda maior veneración y respeto, suplico a $S$. M., que siendo de su agrado, se digne permitir y mandar que de su Real Herario, se presten las cantidades que su Real piedad tenga a bien para que sirvan a dicho fomento en calidad de reintegro, para el tiempo y plazos que se manden devolver, que deveran hacer puntualmente mis herederos; $y$ atendiendo al esmero y fatigas que he tenido para poner en el estado que oy se alla esta Real Fábrica, también suplico rendidamente a $S$. M., que por un efecto de su Real clemencia, se digne distinguir a mis hijos y herederos con alguna pensión que fuere de su Real agrado...».
\end{abstract}

Por último, hay que decir que el mismo día de la fecha que se extendía el testamento, también se celebraban los esponsales de $D$. Tomás Pérez

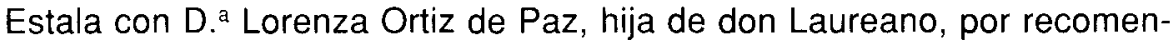
dación de éste con todo gusto y complacencia; pero con la advertencia de que el matrimonio no se pudiera celebrar sin obtener la real aprobación que para el caso se requería, deseando el otorgante la mayor brevedad y, desde luego, dando su más solemne consentimiento.

Como consecuencia de estos esponsales y habiendo dejado ordenado en la escritura de vinculación, que entre sus cuatro herederos se nombrase a aquel que fuera más adecuado para la dirección de la fábrica, declaraba que luego que se casasen, se encargase don Tomás de todo en la fábrica, obras y artefactos, sin que ninguno de los herederos se lo pudiera impedir.

El capital activo que dejó a su fallecimiento, según resulta del inventario hecho con ese motivo, fue de 9.825 .465 rs. y $30 \mathrm{mrs}$., del cual rebajando 4.708 .279 rs. y 27 mrs., que importaron las deudas en su contra y las numerosas mandas, donaciones que hizo, etc., quedaron líquidos 5.117 .185 rs. y $3 \mathrm{mrs}$.

\title{
6. PROCEDENCIA DEL CAPITAL
}

La acumulación del capital que fue la base financiera de la concentración de los medios de producción, tanto de la Real Compañía como de la fábrica de don Laureano, o, incluso, de las de otros fabricantes como Arranz de la Torre y José Manuel Ramiro -fabricantes estos últimos que llegaron a juntar en sus fábricas de 15 a 20 telares-, se debía al capital comercial generado en el comercio de la lana con el exterior. 
En el archivo de la Delegación de Hacienda de Segovia existe un libro titulado: Administración de la Renta General de lanas de Quenta de S. M., en Segovia, en el que se facilitan los nombres de los que mandaban lanas al extranjero en 1751 y la lista de fabricantes de paños. Pues bien, cotejando dichas listas se observa que 13 personas eran a la vez fabricantes de paños y exportadores de lana, formando parte del reducido grupo de fabricantes que producían más de 100 paños anuales.

Se da la circunstancia de que algunos de estos nombres son los mismos que figuran entre los de la lista de accionistas de la Real Compañia. O sea, que se puede concluir, que la mayoría de los capitales de la industria procedian del sector ganadero y de la comercialización de la lana.

Se sabe que en la segunda mitad del siglo xvIII bajó el comercio de lanas con el exterior. Posiblemente estos exportadores invirtieron en fábricas de paños por dos razones: en primer lugar para proteger el capital procedente de las lanas, y, en segundo término, por el aumento de la demanda de paños en el interior - debido al aumento demográfico que se produjo- y a la expansión económica general que se experimentó en España en esta época.

Esta situación provocó en Segovia intensos debates. El dilema estaba en decidirse por la exportación lanera o por la transformación industrial. Se buscaba el equilibrio entre ambas actividades. La polémica era entre ganaderos y fabricantes.

La Sociedad Económica Segoviana de Amigos del País inició una encuesta entre los afectados con el fin de intentar buscar una solución satisfactoria para todas las partes. Las respuestas, tanto de unos como de otros, indican una general unanimidad en que las lanas exportadas debían de ser las finas y prohibirse la saca de las bastas. La divergencia aparecía en la opinión sobre si la exportación perjudicaba a la industria. Los comerciantes de lana, ganaderos y fabricantes extractores de lana, declaraban que no; mientras que los fabricantes no extractores, que sí. Estos alegaban que la extracción de lana provocaba el aumento del precio de la esta, por lo que los fabricantes con poco caudal no podían disponer de materia prima; $y$, además, se facilitaba la competencia a los paños extranjeros, que eran en su mayoría fabricados con lanas españolas.

La postura de la S. E. S. de Amigos del País ${ }^{46}$ fue la de que la extracción no perjudicaba a la industria. Si algún industrial no podía abastecerse

46 AMS, Memoria de la Sociedad Económica de Amigos del País de Segovia, Tomo I, pp. 162-199; tomo II, pp. 316-326; tomo IV, pp. 30-39. 
de lana por la carestía de la misma, se debía a su ineptitud para atesorar caudal como consecuencia de no efectuar mejoras técnicas en su fábrica, que le reportasen más beneficios al ahorrar costes. O sea, que no se abastecía de lana porque no tenía capital, no porque ésta fuera cara.

El ejemplo de los fabricantes extranjeros era elocuente. Estos tenían que pagar los gastos de extracción de la lana y el transporte hasta sus países respectivos, $y$, sin embargo, competían ventajosamente con los paños segovianos. Los gastos de extracción y transporte ascendían al $28 \%$ del precio del paño una vez acabado. Si los fabricantes españoles conseguian reducir los gastos de fabricación mediante el adelanto técnico, resultaría evidente que los extranjeros no podrían competir con los paños segovianos, pues aquellos se ahorrarían el $28 \%$ que tenían de recargo los extranjeros.

Las razones principales de que los productos segovianos no pudiesen competir con los que provenían de otras naciones, no eran otras que el atraso técnico y la persistencia de las ordenanzas gremiales. La prohibición de la exportación de lanas provocaría la ruina de la ganadería, que era una de las fuentes principales de riqueza de Castilla; pues la capacidad de transformación de las manufacturas era muy inferior al contingente de lana que se producía, los precios caerian, desaparecerían los rebaños y no por ellos se desarrollarían las manufacturas.

Sirva como ejemplo de lo dicho que a lo largo del siglo XVIII la cantidad de lana que consumian los telares segovianos era de unas 20000 arrobas, lo que significaba un $15 \%$ de la cantidad que se exportaba.

\section{LA COMERCIALIZACIÓN DE LOS PAÑOS}

Los mercados se extendían a toda Castilla, siendo Madrid el principal punto de destino, a pesar de que nunca los paños segovianos lograron las exenciones fiscales que los productos de otros centros textiles. También salían paños a los mercados americanos por los puertos del norte y del sur de la Península.

La comercialización la efectuaban los mercaderes. Sólo las grandes fábricas de la segunda mitad del XVIII comercializaron directamente el paño. Así el capital industrial se hallaba sometido al capital comercial. Esto repercutía en la calidad de la producción, pues los mercaderes seguros de vender, admitían paños de mala calidad y al fabricante lo único que le interesaba era acabar a tiempo su producto. En 1724 se llegó a proponer la creación de un almacén de paños en la ciudad, con el fin de librar a los fabricantes de la servidumbre del capital comercial y, en definitiva, de mejo- 
rar la calidad de los tejidos. No se llegó a materializar esta idea por la oposición de los comerciantes ${ }^{47}$.

\section{HEREDEROS DE ORTIZ DE PAZ}

Los herederos de don Laureano siguieron unidos en la continuación de los negocias de la "Casa Grande», hasta el 31 de mayo de 1805, fecha en la que fue preciso arreglar las cuentas por haber fallecido - siendo menor de edad y sin descendencia- el día 28 de abril de ese mismo año, el nieto de don Laureano, D. Manuel de Bustinaga, y quedar, por consiguiente, como únicos herederos de la fábrica los tres hijos de Ortiz de Paz.

En todo el tiempo que duró la asociación, don Tomás fue el encargado de la dirección de la fábrica y de la extracción de lanas al extranjero, con un sueldo anual de 40.000 rs. por ambas actividades, es decir, 20.000 rs. por cada una, así que el año que no embarcaba lana no cobraba más que la mitad de dicho sueldo. Don Santiago Arranz de la Torre estuvo al frente de la fábrica de curtidos, cabaña de ganados y demás granjerías con 24 000 rs. de asignación anual ${ }^{48}$.

Tomás Pérez había nacido en Villel (Teruel) en 1754 y había trabajado de niño en oficios de cuchillero y cerrajero. Después pasó a Zaragoza y Barcelona donde se especializó con diversos maestros cerrajeros. A los 22 años viajó a París y allí se aplicó a todo lo relativo a maquinarias ${ }^{49}$.

Construyó una máquina para un fabricante catalán de corchos. El ingenio, manejado por un oficial, podía hacer 500 pares de suelas de corcho al dia, cuando un oficial manualmente hacia 12 pares. Esta máquina gastaba la cuarta parte de materia prima y lo hacía con mayor perfección.

También viajó por Inglaterra. En 1786 consiguió fabricar una máquina hidráulica muy similar a la de vapor y que era muy superior a las conocidas en otros reinos. La primera máquina de vapor de Watt (1778) se perfeccionó en 1787; aunque la máquina de Tomás Pérez daba la mitad de golpes, el español estaba en primera línea de los adelantos técnicos de la época. También se dedicó a visitar fábricas inglesas con sus últimas novedades y de

47 LARRuga, Eugenio, op. cit. p. 27.

48 AMS, LaINEZ, Marcelo, Revista de la Sociedad Económica Segoviana de amigos dei País, III, núm. 10, día 1 de octubre de 1878 .

49. GonzÁlez EnCiso, Agustín. Estado de la industria en el siglo xvIII: la Fábrica de Guadalajara. Madrid, 1980 , pp. 558-567. 
cuyas máquinas y procedimientos tomó las correspondientes anotaciones. Tomás Pérez construyó dos ingenios y en 1787, tenía montado un taller en Madrid para hacer máquinas de hilar y cardar, que vendía por toda España.

Las mejoras en la fábrica continuaron con sus herederos. Nada más morir don Laureano, D. Tomás Pérez junto con D. Miguel de Bustinaga, solicitaron permiso del Ayuntamiento ${ }^{50}$ para introducir en la fábrica de paños -en el edificio de nueva construcción conocido como «El Lagarto"- las aguas que bajaban por el arroyo inmediato a ella, es decir, el arroyo Clamores, y disfrutar de sus corrientes en cierta máquina que tenía don Tomás dispuesta dentro de la citada fábrica, sin que por esto se siguiera perjuicio alguno a terceros por salir después de su uso sin disminuir y ensuciar el caudal. La máquina que se pretendía instalar era de nueva invención, destinada a mejorar y adelantar en el hilado de la lana. Para ello era necesario encauzar el agua del arroyo Clamores y las demás aguas perdidas que poseía la fábrica - provenientes de la merced de agua que recibía del Acueducto- y dirigirlas al edificio de «El Lagarto» donde se pensaba instalar la nueva máquina.

El Ayuntamiento para tan importante asunto dio comisión el día 25 de noviembre de 1788, a los señores Conde de Santibáñez del Río y D. Francisco Vaca y Cáceres, regidores y procuradores síndicos y personeros del común, y a D. Diego Antonio Robledo, diputado de abastos, para que informasen al especto de ello.

El 31 de enero de 1789 don Tomás volvió a insistir en el asunto, añadiendo que, para evitar cualquier perjuicio, haría a sus expensas un lavadero de piedra «en escamado y con la mexor proporción que fuese posible" y en el sitio que se le señalase.

El Ayuntamiento pidió un informe a D. Juan de la Torre, maestro de obras y aparejador por S. M., de las reales obras de su Casa de Moneda y titular de las del Cabildo Catedral, el día 31 de enero de 1789. Éste contestó que «no contemplaba perjuicio alguno en que se concediese el uso de las citadas aguas", en los términos en que don Tomás proponía en sus memoriales.

El sitio que se buscó para el referido lavadero fue inmediato al arroyo que bajaba de la fuente conocida con el nombre de la Alameda y que salían sus aguas del monasterio de monjas franciscas de San Antonio el Real.

Para tomar el agua del arroyo Clamores con destino a la obra, se haría el punto de captación a la altura de la huerta de Juan Bravo, formando en

50 AMS, Libros de Actas. Sesión correspondiente al día 22 de junio de 1789. 
la madre del arroyo una estacada de madera y piedra, al modo de presa para nivelar el agua con la altura necesaria y sin exceder en nada a la elevación del terreno. El canal que conduciría el agua sería hecho en piedra con el hueco de medio pie en cuadro. $Y$ el resto de la construcción en mampostería de media vara de grueso, cobijado de piedra y recibido con cal en toda su línea con la mayor firmeza, para que no se filtrase el agua.

El informe que dieron los señores comisarios el día 21 de febrero de 1789 fue que no había perjuicio alguno en la construcción de dichas obras

“... siempre que la dicha licencia que se conceda para la construición de dicha obra, sea vaxo de las condiciones que propone en su memorial de 30 de enero deste año, y con arreglo a lo prevenido por el maestro Torres... ${ }^{51}$.

Cuando el 31 de octubre de 1799 se formalizó por primera vez esta Compañia, importaron todos sus haberes 7.799 .038 rs. y 32 mrs., y el 31 de mayo, fecha en que falleció $D$. Manuel de Bustinaga y por tanto quedaron solamente tres socios, ascendía el total de su capital a 9.526 .172 rs. y 4 mrs.; habiendo calculado entonces que hacía falta un capital de 2.148.000 rs., para elaborar anualmente 7.200 arrobas de lana, necesarias para construir 920 piezas de paño que eran los que la fábrica podía producir.

En esta ocasión tasaron el edificio -que entonces llamaban la obra nueva y hoy "El Lagarto" - en 455.582 rs.; el edificio superior o "Casa Grande», en 390.000 rs. y el batán del río Eresma, en 230.000 rs.

Concluida esta sociedad en el año 1805, se reunieron para tratar de buscar el mejor medio de continuar en adelante con los negocios. Decididos en continuar en los sucesivo cada uno de por sí los bienes libres, y a dar la mayor simplificación posible al régimen administrativo de los vinculados, decidieron que lo mejor - siendo ya mayor de edad don Bartolomé- era cederle en arrendamiento la Real Fábrica de paños vinculada, propia de los tres hermanos.

El contrato se hizo por 8 años, hasta el 1 de junio de 1813, obligándose a pagar don Bartolomé a cada uno de sus dos hermanos la cantidad anual de 45.740 rs. y 22 mrs., que les correspondían por los réditos del $6 \%$ de los efectos comerciables y el $2 \%$ de los edificios y utensilios pertenecientes a la vinculación, en cuyas máquinas de hilar don Tomás habia introducido notables reformas y adelantos, algunos de su invención.

El siglo xIX es el de la desaparición completa de la industria pañera en la ciudad de Segovia. El descenso de la producción debió de ser especial-

51 AMS, Merced de agua del Clamores, sig. 860-15. 
mente acelerado a partir de 1825. Según un indicador indirecto, el descenso en el número de bautizado en las parroquias más industriosas, la emigración debió de sacudir a los arrabales duramente a partir de estos años.

La principal causa de la liquidación de la industria pañera fue la falta de renovación tecnológica, lo que facilitó la irresistible competencia de los géneros fabricados en otras regiones, y en especial, en Cataluña. Hacia 1850 Pascual Madoz decía al respecto de las fábricas de Segovia:

\footnotetext{
«Para ellos nada hay como sus fábricas, y así es la verdad, pero les ha faltado la dirección les ha faltado apoyo y hasta la suerte se ha revelado contra ellos; cuando todas las fábricas del reino trabajan incesantemente para mejorar sus manufacturas introduciendo máquinas para competir con los extranjeros, los segovianos han creído de buena fe que la antigua fama de sus paños era bastante para conservarles el aprecio de los consumidores y, sin adelantar nada en su elaboración, antes adulterándolos para poder competir en precios, han derrotado sus capitales en términos que en 1825 estaban reducidos en la nulidad... "5?.
}

Los primeros años del siglo XIX fueron difíciles para los trabajadores segovianos. Hubo numerosas revueltas e incidentes ocasionados por las dificultades laborales y el hambre. En 1817 la fábrica de Ortiz de Paz resultó incendiada y, a pesar de haber cortado el fuego, se perdió un gran capital. Se volvió a invertir en ella otra cantidad similar para su reedificación, pero no pudo sobreponerse desde entonces, declarándose en decadencia a partir de este incidente. La producción fundamental en estas horas bajasera básicamente le elaboración de hilazas para otras fábricas, bajando su producción pañera a la cantidad de 70 ó 75 paños al año.

Las palabras de Madoz parecen certeras en lo fundamental, aunque hay que dejar constancia también de que una minoría de fabricantes si fueron conscientes de los riesgos que comportaba la excesiva confianza en el prestigio tradicional de los géneros segovianos y la falta de iniciativas para introducir las innovaciones técnicas de la época. Esa minoría no contempló pasivamente el derrumbe de la pañeria e, individualmente o formando compañías, lograron crear algunos establecimientos avanzados, que, a pesar de todo, también fracasaron. Algunos de ellos a causa de incendios cuya autoría se debía a los mismos que, desplazados por las máquinas, recurrían a la práctica del "ludismo" como recurso extremo para defender sus puestos de trabajo.

52 Madoz, Pascual. Diccionario Histórico Estadistico. Segovia, Tomo VI , p. 216. 


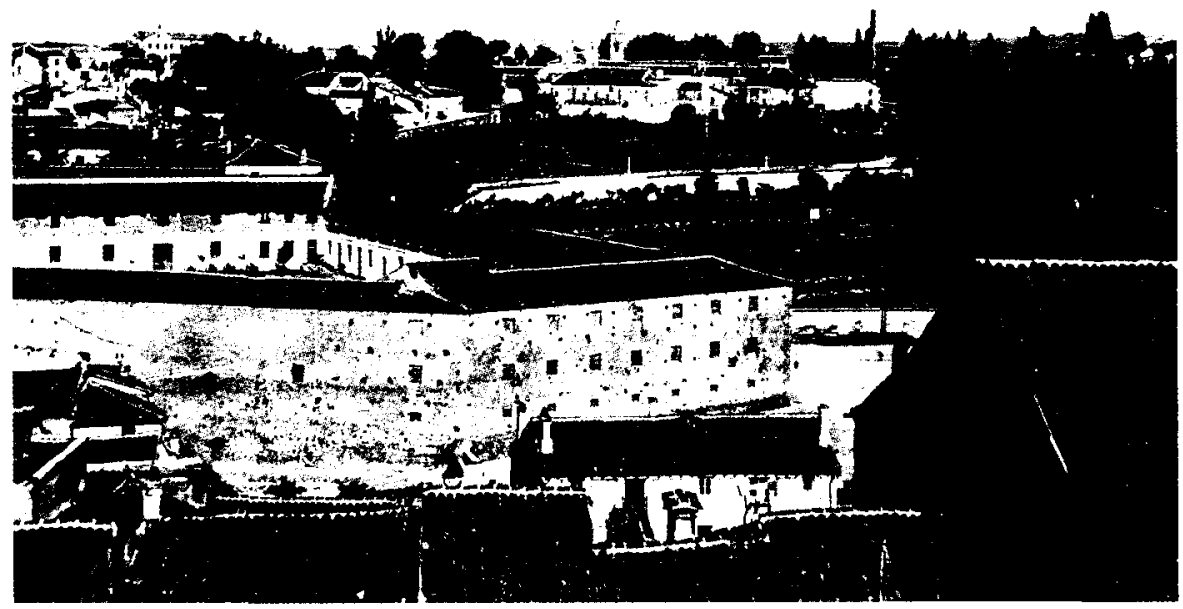

En primer plano el edificio conocido como “El Lagarto", y en segundo término, la "Casa Grande». Fotografía de la segunda mitad del siglo xix. Colección particular.

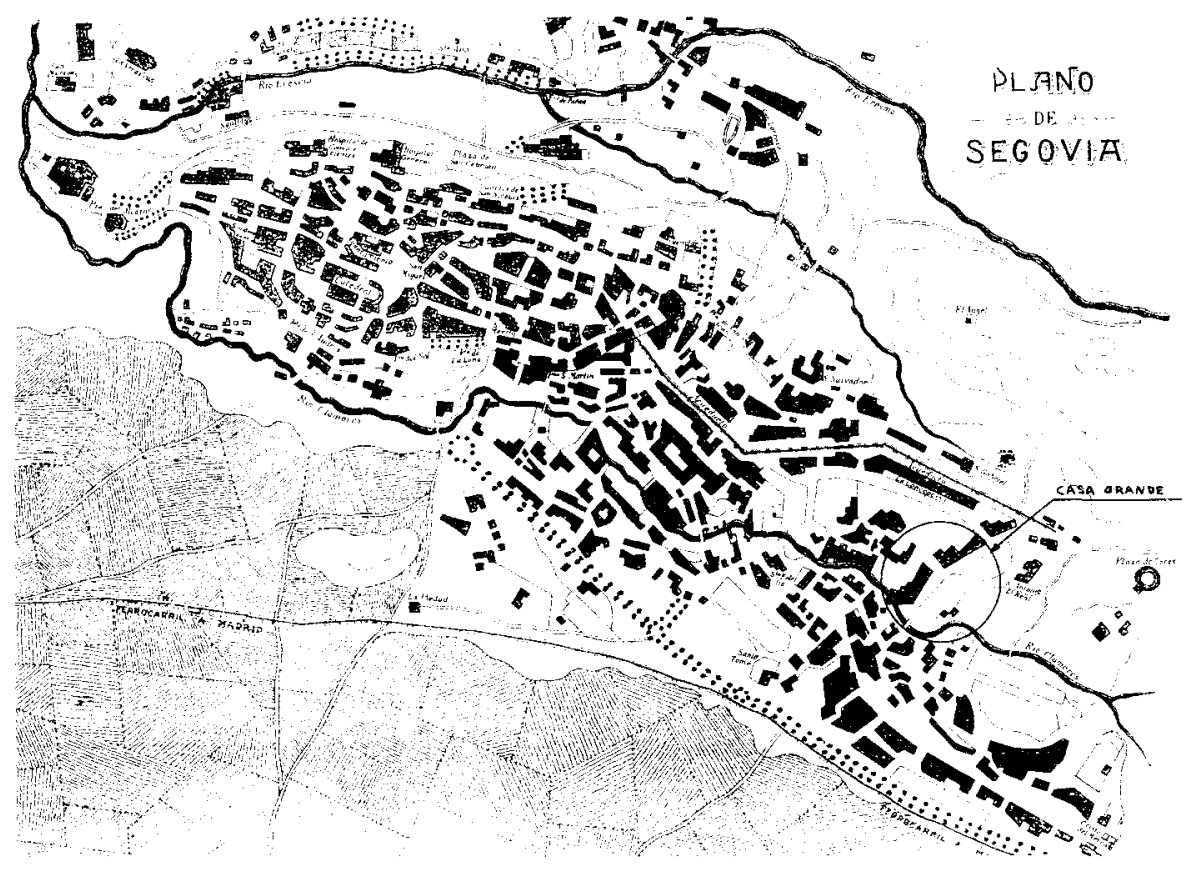

Plano de situación. Rodeada con un círculo, la Fábrica Real de Ortiz de Paz. Archivo Municipal de Segovia. 